\title{
Title: Mitochondrial respiration contributes to the interferon gamma response in antigen presenting cells
}

Short-title: Interferon gamma signaling requires complex I

Authors: Michael C. Kiritsy ${ }^{\mathrm{a}}$, Daniel Mott ${ }^{\mathrm{a}}$, Samuel M. Behar ${ }^{\mathrm{a}}$, Christopher M. Sassetti ${ }^{\mathrm{a}}$, Andrew J. Olive ${ }^{\text {b\# }}$

${ }^{\mathrm{a} D e p a r t m e n t ~ o f ~ M i c r o b i o l o g y ~ a n d ~ P h y s i o l o g i c a l ~ S y s t e m s, ~ U n i v e r s i t y ~ o f ~ M a s s a c h u s e t t s ~ M e d i c a l ~}$ School, 55 Lake Ave. N, Worcester, Massachusetts 01655, USA.

${ }^{\mathrm{b}}$ Department of Microbiology \& Molecular Genetics, Michigan State University, 567 Wilson

\# Co-corresponding Author

\section{Correspondence:}

Christopher Sassetti

christopher.sassetti@umassmed.edu

Dept. of Microbiology and Physiological Systems

University of Massachusetts Medical School

368 Plantation St. ASC8-2051

Worcester, MA 01605

(508) 856-3678

Andrew Olive

oliveand@msu.edu

Department of Microbiology and Molecular Genetics

36 East Lansing, MI 48824

37 (517) 884-5367 


\section{Abstract:}

44 The immunological synapse allows antigen presenting cells (APC) to convey a wide array of

45 functionally distinct signals to T cells, which ultimately shape the immune response. The relative

46 effect of stimulatory and inhibitory signals is influenced by the activation state of the APC,

47 which is determined by an interplay between signal transduction and metabolic pathways. While

48 toll-like receptor ligation relies on glycolytic metabolism for the proper expression of

49 inflammatory mediators, little is known about the metabolic dependencies of other critical

50 signals such as interferon gamma (IFN $\gamma$ ). Using CRISPR-Cas9, we performed a series of

51 genome-wide knockout screens in macrophages to identify the regulators of IFN $\gamma$-inducible $\mathrm{T}$

52 cell stimulatory or inhibitory proteins MHCII, CD40, and PD-L1. Our multi-screen approach

53 enabled us to identify novel pathways that control these functionally distinct markers. Further

54 integration of these screening data implicated complex I of the mitochondrial respiratory chain in

55 the expression of all three markers, and by extension the IFN $\gamma$ signaling pathway. We report that

56 the IFN $\gamma$ response requires mitochondrial respiration, and APCs are unable to activate T cells

57 upon genetic or chemical inhibition of complex I. These findings suggest a dichotomous

58 metabolic dependency between IFN $\gamma$ and toll-like receptor signaling, implicating mitochondrial

59 function as a fulcrum of innate immunity. 
Introduction:

During the initiation of an adaptive immune response, the antigen presenting cell (APC) serves as an integration point where tissue-derived signals are conveyed to T cells. Myeloid APCs, such as macrophages and dendritic cells (DCs), are responsible for the display of specific peptides in complex with MHC molecules, and for the expression of co-signaling factors that tune the $\mathrm{T}$ cell response (1). The expression of stimulatory or inhibitory co-signaling molecules depends on the

71 local immune environment and activation state of the APC (2). In particular, interferon gamma

72 (IFN $\gamma$ ) stimulates the surface expression of MHC proteins (3-9), co-stimulatory proteins such as

73 CD40, and the secretion of cytokines like IL-12 and IL-18 (10), to promote T cell activation and the production of IFN $\gamma$-producing T-helper type 1 (Th1) effector cells (11-15). In the context of local inflammation, pattern recognition receptor (PRR) ligands and endogenous immune activators can collaborate with IFN $\gamma$ to induce the expression of co-inhibitory molecules, like programmed death-ligand 1 (PD-L1) (16-22), which ligates T cell programmed death receptor 1 (PD1) to limit immune activation and mitigate T cell-mediated tissue damage (23-26).

IFN $\gamma$ mediates these complex effects via binding to a heterodimeric surface receptor (27-

81 30). The subunits of the complex, IFNGR1 and IFNGR2, assemble once IFNGR1 is bound by its

82 ligand $(31,32)$. Complex assembly promotes the phosphorylation of janus kinases 1 and 2 (JAK1

83 and JAK2) followed by activation of the signal transducer and activation of transcription 1

84 (STAT1) (33). Phosphorylated STAT1 then dimerizes and translocates to the nucleus to activate

85 the transcription of genes containing promoters with IFN $\gamma$-activated sequences (GAS), which

86 includes other transcription factors such as interferon regulatory factor 1 (Irf1) that amplify the

87 expression of a large regulon that includes T cell co-signaling molecules $(34,35)$. The 
importance of this signaling pathway is evident in a variety of diseases including cancer (36-40), autoimmunity $(41,42)$, and infection (43). Individuals with inborn deficiencies in IFN $\gamma$

90 signaling, including mutations to the receptor $(44,45)$, suffer from a defect in Th1 immunity that

91 results in an immunodeficiency termed Mendelian susceptibility to mycobacterial disease

92 (MSMD) (46-49). Conversely, antagonists of IFN $\gamma$-inducible inhibitory molecules, such as PD-

$93 \mathrm{~L} 1$, are the basis for checkpoint inhibitor therapies that effectively promote $\mathrm{T}$ cell-mediated

94 tumor destruction $(26,28,50-55)$. While the obligate components of the IFN $\gamma$ signaling pathway

95 are well known, characterization of additional regulators of this response promises to identify

96 both additional causes of immune dysfunction and new therapeutic targets.

100 glycolytic metabolism and this shift in catabolic activity is essential for cellular activation,

101 migration, and CD4+ and CD8+ T cell activation $(18,56-70)$. The metabolic state of the $\mathrm{T}$ cell is

102 also influenced by the local environment and determines both effector function and long-term

103 differentiation into memory cells $(71,72)$. Like PRR signaling, IFN $\gamma$ stimulation has been

104 reported to stimulate glycolysis and modulate cellular metabolism in macrophages $(66,73)$.

105 However, the effects of different metabolic states on IFN $\gamma$-stimulated APC function remains

106 unclear. 
111 MHCII, CD40, and PD-L1. We identified positive and negative regulators that controlled each

112 marker, underscoring the complex regulatory networks that influence the interactions between

113 APCs and T cells. Pooled analysis of the screens uncovered shared regulators that contribute to

114 the global IFN $\gamma$ response. Prominent among these general regulators was complex I of the

115 respiratory chain. We report that the activity of the IFN $\gamma$ receptor complex and subsequent

116 transcriptional activation depends on mitochondrial function in both mouse and human myeloid

117 cells. Experimental perturbation of respiration inhibits the capacity of both macrophages and

118 dendritic cells to stimulate T cells, identifying mitochondrial function as a central point where

119 local signals are integrated to determine APC function.

121 Results

Forward genetic screen identifies regulators of IFN $\gamma$-inducible MHCII, CD40 and PD-L1 cell surface expression.

127 examined the expression of three functionally distinct cell surface markers that are induced by

128 IFN $\gamma$. Stimulation of Cas9-expressing immortalized bone marrow-derived macrophages with

129 IFN $\gamma$ for 24 hours resulted in the upregulation of $\mathrm{T}$ cell stimulatory molecules, major

130 histocompatibility complex class II (MHCII) and CD40, and the inhibitory ligand PD-L1

131 (Cd274), on the cell surface (Figure 1A). To identify genes that regulate the expression of these

132 markers, Cas9-expressing macrophages were transduced with a lentiviral genome-wide knockout

133 (KO) library containing four single guide RNAs (sgRNAs) per protein-coding gene and 1000 
134 non-targeting control (NTC) sgRNAs (74). The knockout library was then stimulated with IFN $\gamma$,

135 and fluorescently activated cell sorting (FACS) was used to select for mutants with high or low

136 cell surface expression of each individual marker (Figure 1B). For each of the three surface

137 markers, positive and negative selections were performed in duplicate. The sgRNAs contained in

138 the input library and each sorted population were amplified and sequenced (Figure 1A,B).

To estimate the strength of selection on individual mutant cells, we specifically assessed

140 the relative abundance of cells harboring $\operatorname{sgRNAs}$ that target each of the surface markers that

141 were the basis for cell sorting. When the abundances of sgRNAs specific for $H 2-A b 1$ (encoding

142 the MHCII, H2-I-A beta chain), Cd40, or Cd274 (PD-L1) were compared between high- and

143 low-expressing cell populations, we found that each of these sgRNAs were significantly depleted

144 from the cell populations expressing the targeted surface molecule, while each had no consistent

145 effect on the expression of non-targeted genes (Figure 1C). While not all individual sgRNAs

146 produced an identical effect, we found that targeting the genes that served as the basis of sorting

147 altered the mean relative abundance 30-60 fold, demonstrating that all selections efficiently

148 differentiated responsive from non-responsive cells.

150 employs a generalized linear model to identify genes, and by extension regulatory mechanisms,

151 controlling the expression of each surface marker. This analysis correctly identified the

152 differential representation of sgRNAs targeting genes for the respective surface marker in the

153 sorted populations in each screen, which were found in the top 20 ranked negative selection

154 scores (Ranks: $H 2-A b 1=20, C d 40=1, C d 274=3$; Table S1). Upon unsupervised clustering of

$155 \beta$ scores for the most highly enriched genes in each screen (top 5\%, positive or negative) both

156 common and pathway-specific effects were apparent (Figure 1D; Table S2). A small number of 
genes assigned to Cluster 1, including the IFN $\gamma$ receptor components (Ifngrl and Ifngr2), were

strongly selected in the non-responsive population in all three selections. However, many

mutations appeared to preferentially affect the expression of individual surface markers,

161 to specifically control MHCII transcription, such as Ciita, Rfx5, Rfxap, Rfxank, and Creb1 (8, 76-

162 78) were found in Cluster 4 along with several novel regulators that appear to be specifically

163 required for this pathway. MHCII-specific factors are reported in an accompanying study (79).

167 CD40 expression in hematopoietic progenitors (80), and we confirmed this observation in

168 macrophages (Figure 1E). We observed a 6-fold higher induction of CD40 in macrophages

169 stimulated with a combination of IFN $\gamma$ and TNF compared to IFN $\gamma$ alone. This synergy was

170 specific to CD40 induction, as we did not observe any enhancement of IFN $\gamma$-induced MHCII

171 expression by TNF addition.

Several recent studies identified genes that control PD-L1 expression in cancer cell

173 lines(28, 53, 55, 81-86), and we validated the PD-L1-associated clusters using these candidates.

174 Our analysis found the previously-described negative regulators, Irf2 (87), Keapl, and Cul3 (88-

$17590)$ in the PD-L1-related Cluster 7, along with novel putative negative regulators such as the

176 oligosaccharlytransferase complex subunit Ostc and the transcriptional regulator, Cnbp. We

177 generated knockout macrophages for each of these novel candidates and confirmed that mutation

178 of these genes enhances the IFN $\gamma$-dependent induction of PD-L1 surface levels (Figure 1F). 
179 Cumulatively, these data delineate the complex regulatory networks that shape the IFN $\gamma$

180 response.

Mitochondrial complex $I$ is a positive regulator of the IFN $\gamma$ response.

To identify global regulators of the IFN $\gamma$ response, we performed a combined analysis,

reasoning that treating each independent selection as a replicate measurement would increase our power to identify novel pathways. We used MAGeCK to calculate a selection coefficient $(\beta)$ for each gene by maximum likelihood estimation (75). By combining the 24 available measurements

187 for each gene (three different markers, each selection in duplicate, and four sgRNAs per gene),

188 we found that the resulting selection coefficient reflected the global importance of a gene for the

189 IFN $\gamma$ response (Table S3). The most important positive regulators corresponded to the proximal

190 IFN $\gamma$ signaling complex (Figure 2A). Similarly, we identified known negative regulators of IFN $\gamma$

191 signaling, including the protein inhibitor of activated Stat1 (Pias1) (91), protein tyrosine

192 phosphatase non-receptor type 2 (Ptpn2) (84), Mitogen activate protein kinase 1 (Mapk1), and

193 suppressor of cytokine signaling 1 (Socs 1$)$ and 3 (Socs3).

194 We performed gene set enrichment analysis (GSEA) using a ranked list of positive

195 regulators from the combined analysis (Table S4) (92). Among the top enriched pathways was a

196 gene set associated with type II interferon (e.g., IFN $\gamma$ ) signaling (normalized enrichment score $=$

1972.45 , q-value $=7.98 \mathrm{e}-5$ ), validating the approach. GSEA identified a similarly robust enrichment

198 for gene sets related to mitochondrial respiration and oxidative phosphorylation (Figure 2B). In

199 particular, we found a significant enrichment of gene sets dedicated to the assembly and function

200 of the NADH:ubiquinone oxidoreductose (hereafter, "complex I") of the mitochondrial

201 respiratory chain. Complex I couples electron transport with NADH oxidation and is one of four 
202 protein complexes that comprise the electron transport chain (ETC) that generates the

203 electrochemical gradient for ATP biosynthesis. To confirm the GSEA results, we examined the

204 combined dataset for individual genes that make up each complex of the ETC (Figure 2C). This

205 analysis demonstrated that sgRNAs targeting components of complexes II, III or IV had minimal

206 effects on the expression of the IFN $\gamma$-inducible surface markers tested. In contrast, the disruption

207 of almost every subunit of complex I impaired the response to IFN $\gamma$, with the notable exception

208 of $N d u f a b 1$. As this gene is essential for viability (93), we assume that cells carrying Ndufabl

209 sgRNAs retain functional target protein.

210 To investigate the contribution of specific complex I components to different IFN $\gamma$ -

211 stimulated phenotypes, we reviewed the surface marker-specific enrichment scores for genes that

212 contribute to the complex assembly, the electron-accepting N-module, or the electron-donating Q

213 module (93-98). Of the 48 individual assembly factors or structural subunits of complex I present

214 in our mutant library, 29 were significantly enriched as positive regulators in the global analysis

215 and were generally required for the induction of all IFN $\gamma$-inducible markers (Fig. 2D). The

216 enrichment for each functional module in non-responsive cells was statistically significant.

217 However, not all individual complex I components were equally enriched, which could reflect

218 either differential editing efficiency or distinct impacts on function. To investigate the latter

219 hypothesis, we compared our genetic data with a previous proteomic study that quantified the

220 effect of individual complex I subunits on the stability of the largest subcomplex, the N-module

221 (93). For a given subunit, we found a significant correlation between the magnitude of

222 enrichment in our genetic screen and its effect on the structural stability of the module (Fig. 2E),

223 specifically implicating the activity of complex I in the IFN $\gamma$ response. 
To directly test the predictions of the screening data, we used CRISPR to generate individual macrophage lines that were deficient for complex I subunits. We first validated the expected metabolic effects of complex I disruption by comparing the intracellular ATP levels in

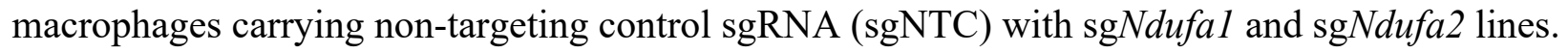

228 When cultured in media containing the glycolytic substrate, glucose, all cell lines produced 229 equivalent amounts of ATP (Figure 3A). However, when pyruvate was provided as the sole 230 carbon source, and ATP generation depends entirely upon flux through ETC and oxidative

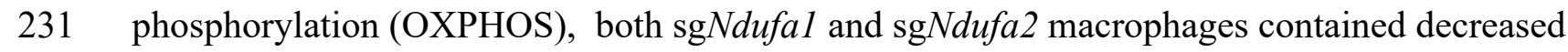
232 ATP levels compared to sgNTC cells (Figure 3B). To confirm the glycolytic dependency of 233 complex I mutant macrophages, we grew cells in complete media with glucose and treated with 234 the ATP synthase (complex V) inhibitor, oligomycin, which blocks ATP generation by OXPHOS. While oligomycin reduced ATP levels in sgNTC macrophages, this treatment had no

236 effect in sgNdufal and sgNdufa2 cells (Supplementary Figure 1A), confirming that these

237 complex I-deficient cells rely on glycolysis for energy generation. IFN $\gamma$ treatment slightly

238 reduced ATP levels in glucose containing media but did not differentially affect cell lines (Figure

$2393 \mathrm{~A})$. Throughout these experiments we found that the sgNdufal mutant showed a greater

240 OXPHOS deficiency than the sgNdufa2 line.

We next compared the response to IFN $\gamma$ in macrophages lacking $N d u f a 1$ and $N d u f a 2$ with

242 those carrying CRISPR-edited alleles of Ifngrl or the negative regulator of signaling, Ptpn2. As

243 CD40 was found to rely on more complex inputs for expression, which include TNF (Figure 1E),

244 we relied on MHCII and PD-L1 as markers of the IFN $\gamma$ response for subsequent studies. As

245 expected, and consistent with the genetic screen, we found that the loss of Ifngr1 or Ptpn2 either

246 abrogated or enhanced the response to IFN $\gamma$, respectively. Also consistent with predictions, 
mutation of complex I genes significantly reduced the IFN $\gamma$-dependent induction of MHCII and

PD-L1 compared to sgNTC (Figure 3C-F). The Ndufal mutation that abrogates OXPHOS, reduced MHCII induction to the same level as Ifngrl-deficient cells. To confirm these results using an orthologous method we treated cells with the complex I inhibitor, rotenone (99). This treatment caused a dose-dependent inhibition of the IFN $\gamma$-induced MHCII expression in $\operatorname{sgNTC}$ macrophages (Figure 3G) and had a similar inhibitory effect on the residual IFN $\gamma$ response in

Ndufa2-deficient cells. Together these results confirm that complex I is required for the induction

254 of immunomodulatory surface molecules in response to IFN $\gamma$.

To investigate what aspect of mitochondrial respiration contributes to the IFN $\gamma$ response,

256 we inhibited different components of the ETC. All inhibitors were used at a concentration that

257 abrogated OXPHOS-dependent ATP generation (Supplementary Figure 1B). The complex V

258 inhibitor, oligomycin, inhibited the IFN $\gamma$-induced MHCII expression, albeit to a lesser extent

259 than direct complex I inhibition with rotenone (Figure $3 \mathrm{H}$ ). This partial effect could reflect an

260 inability to dissipate the proton motive force (PMF), which inhibits electron flux throughout the

261 ETC, including through complex I (100). Carbonyl cyanide m-chlorophenyl hydrazone (CCCP)

262 disrupts mitochondrial membrane potential and OXPHOS while preserving electron flux. CCCP

263 had no effect on the IFN $\gamma$ response, indicating that ATP generation is dispensable for

264 IFN $\gamma$ responsiveness and highlighting a specific role for complex I activity.

We then altered the media composition to test the sufficiency of mitochondrial respiration

267 MHCII expression to a similar degree in macrophages cultured in complete media with glucose

268 as in media containing only pyruvate or citrate, which must be catabolized via mitochondrial

269 respiration (Figure 3H). Inhibition of mitochondrial pyruvate import with the chemical inhibitor, 
UK5099 (101), abrogated MHCII induction in cultures grown in pyruvate, but not in citrate,

271 which is imported via a UK5099-independent mechanism. Taken together these results suggest

272 that cellular respiration is both necessary and sufficient for maximal expression of the IFN $\gamma-$

273 inducible surface markers MHCII and PD-L1.

Mitochondrial function is specifically required IFN $\gamma$-dependent responses.

The mitochondrial-dependency of the IFN $\gamma$ response contrasted with the known

277 glycolytic-dependency of Toll-like receptor (TLR) signaling, suggesting that TLR responses

278 would remain intact when complex I was inhibited. Indeed, not only were TLR responses intact

279 in $\operatorname{sgNdufal}$ and $\operatorname{sgNdufa} 2$ mutant macrophages, these cells secreted larger amounts of TNF or

280 IL-6 than sgNTC cells in response to the TLR2 ligand, Pam3CSK4. (Figure 4A). Thus, the

281 glycolytic dependency of these cells enhanced the TLR2 response, indicating opposing metabolic

282 dependencies for IFN $\gamma$ and TLR signaling.

Whether the effects of complex I on macrophage responsiveness was the result of

284 reduced mitochondrial respiratory function or secondary to cellular stress responses, such as

285 radical generation, remained unclear. To more directly relate mitochondrial function to these

286 signaling pathways, we created cell lines with reduced mitochondrial mass. Macrophages were

287 continuously cultured in linezolid (LZD), an oxazolidinone antibiotic that inhibits the

288 mitochondrial ribosome (102-104). This treatment produced a cell line with $~ 50 \%$ fewer

289 mitochondrial genomes per nuclear genome and a corresponding decrease in OXPHOS capacity,

290 compared to control cells grown in the absence of LZD (Figure 4B,C). Cells were cultured

291 without LZD for 16 hours and then stimulated with either IFN $\gamma$ or Pam3CSK4. Consistent with

292 our complex I inhibition studies, we found this reduction in mitochondrial mass nearly abrogated 
293 the IFN $\gamma$-dependent induction of MHCII (Figure 4D), while the TLR2-dependent secretion of

294 TNF and IL-6 was preserved or enhanced (Figure 4E and 4F). Thus, mitochondrial activity,

295 itself, is necessary for a robust IFN $\gamma$ response.

296 To further address potential secondary effects of mitochondrial inhibition on the

297 IFN $\gamma$ response, we investigated the role of known oxygen or nitrogen radical-dependent

298 regulators (Supplementary Figure 1C-G). Inhibition of ROS generation by replacing glucose

299 with galactose $(66,100,105)$ had no effect on IFN $\gamma$-induced MHCII induction. Similarly,

300 neutralization of cytosolic or mitochondrial radicals with $\mathrm{N}$-acetylcysteine or MitoTempo,

301 respectively, had no effect on MHCII induction either alone or in combination with ETC

302 inhibition. The role of the cytosolic redox sensor, $\operatorname{HIF} 1 \alpha(106,107)$ was addressed by

303 chemically stabilizing this factor with dimethyloxalylglycine (DMOG). A potential role for nitric

304 oxide production was addressed with the specific NOS2 inhibitor $1400 \mathrm{~W}(60,66,108)$. Neither

305 of these treatments affected IFN $\gamma$-induced MHCII cell surface expression in the presence or

306 absence of simultaneous Pam3CSK4, further supporting a direct relationship between

307 mitochondrial respiratory capacity and the IFN $\gamma$ response.

309 Complex I is specifically required for IFN $\gamma$ signaling in human cells.

310 To understand the function of complex I during IFN $\gamma$-stimulation in human cells, we used

311 monocyte-derived macrophages (MDM) from peripheral blood of healthy donors. As in our

312 mouse studies, we assessed the response of these cells to IFN $\gamma$ or Pam3CSK4 by quantifying the

313 abundance of IFN $\gamma$-inducible surface markers or cytokines that were optimized for human cells.

314 Since HLA-DR is not strongly induced by IFN $\gamma$, we included ICAM1 in addition to CD40 and

315 PD-L1 as surface markers. As seen in the murine model, rotenone inhibited the IFN $\gamma$-mediated 
316 induction of all three markers (Figure 5A). TLR2 responses were assessed by the production of

317 TNF and IL-1 $\beta$. Upon Pam3CSK4 stimulation, rotenone significantly enhanced the secretion of

318 IL-1 $\beta$ and TNF (Figure 5B). While simultaneous treatment with both IFN $\gamma$ and Pam3CSK4

319 produced the previously described inhibition of IL-1 $\beta$ (109), rotenone still did not decrease the

320 production of these TLR2 dependent cytokines. Thus, as we observed in mouse cells, complex I

321 is specifically required for IFN $\gamma$ signaling in human macrophages.

\section{Complex I inhibition reduces IFN $\gamma$ receptor activity.}

To understand how complex I activity was shaping the IFN $\gamma$ response, we first

325 determined whether its effect was transcriptional or post-transcriptional by simultaneously

326 monitoring mRNA and protein abundance over time. Surface expression of PD-L1 was

327 compared with the gene's mRNA abundance, while the surface expression of MHCII was

328 compared with the mRNA abundance of Ciita, the activator of MHCII expression that is initially

329 induced by IFN $\gamma$ (Figure 6 A,B). In both cases, mRNA induction preceded surface expression of

330 the respective protein. More importantly, both mRNA and protein expression of each marker was

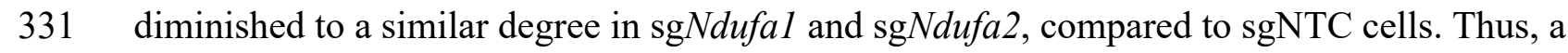

332 deficit in transcriptional induction could account for the subsequent decrease in surface

333 expression observed in complex I deficient cells.

IFN $\gamma$ rapidly induces the transcription of a large number of STAT1 target genes,

335 including IRF1, which amplifies the response. The relative impact of complex I inhibition on the

336 immediate transcriptional response versus the subsequent IRF1-dependent amplification was

337 initially assessed by altering the timing of complex I inhibition. As the addition of rotenone was

338 delayed relative to IFN $\gamma$ stimulation, the ultimate effect on MHCII expression was diminished 
339 (Figure 6C). If rotenone was added more than 4 hours after IFN $\gamma$, negligible inhibition was

340 observed by 24 hours, indicating that early events were preferentially impacted by rotenone. To

341 more formally test the role of IRF1, this study was performed in macrophages harboring a

342 CRISPR-edited Irfl gene. While the level of MHCII induction was reduced in the absence of

343 IRF1, the relative effect of rotenone addition over time was nearly identical in $\operatorname{sg} I r f 1$ and sgNTC

344 cells. Thus, mitochondrial function appeared to preferentially impact the initial transcriptional

345 response to IFN $\gamma$ upstream of IRF1.

346 Ligand induced assembly of the IFNGR1-IFNGR2 receptor complex results in the

347 phosphorylation and transactivation of janus kinases 1 and 2 (JAK1, JAK2).

348 Autophosphorylation of JAK2 at tyrosine residues 1007/1008 positively regulates this cascade

349 and serves as a marker of JAK2 activation. These activating events at the cytoplasmic domains

350 of the IFNGR receptor complex facilitate STAT1 docking and phosphorylation at tyrsone-701

351 (Y701), a prerequisite for the IFN $\gamma$ response. Additional STAT1 phosphorylation at serine-727

352 can amplify signaling. To determine if complex I is required for these early signal transduction

353 events, we examined the activation kinetics by immunoblot (Figure 6D). The total abundances of

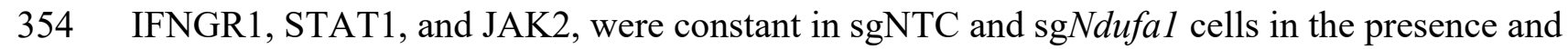

355 absence IFN $\gamma$-stimulation. While we detected robust phosphorylation of JAK2 Y1007/8, STAT1-

356 Y701, and STAT1-S727 over time following IFN $\gamma$ treatment in sgNTC cells, phosphorylation at

357 all three sites was both delayed and reduced across the time-course in sgNdufal cells. We

358 conclude that the loss of complex I function inhibits receptor proximal signal transduction

359 events. 
361 Mitochondrial respiration in antigen presenting cells is required IFN $\gamma$-dependent $\mathbf{T}$ cell

362

\section{activation.}

As respiration affected both stimulatory and inhibitory antigen presenting cell (APC)

functions, we sought to understand the ultimate effect of mitochondrial function on $\mathrm{T}$ cell activation. To this end, we generated myeloid progenitor cell lines from Cas9-expressing transgenic mice that can be used for genome-edited and differentiated into either macrophages or dendritic cells using M-CSF or FLT3L, respectively $(110,111)$. Macrophages differentiated from these myeloid progenitors demonstrated robust induction of all three markers that were the basis for the IFN $\gamma$ stimulation screens (Supplementary Figure 2A-C). Further, both the IFN $\gamma$-mediated upregulation of these markers and the inhibitory effect of rotenone or oligomycin on their induction were indistinguishable from wild-type primary bone marrow-derived macrophages (Supplementary Figure 2D-F). In both macrophages and in dendritic cells (DCs), the induction of MHCII by IFN $\gamma$ was inhibited by rotenone and oligomycin (Figure 7A). Unlike macrophages, murine DCs basally express MHCII and these inhibitors only repressed the further induction by IFN $\gamma($ Figure 7A,B).

Both macrophages and DCs were used to determine if the inhibition of complex I in APCs reduces T cell activation. Both types of APCs were stimulated with IFN $\gamma$ overnight with or without rotenone before washing cells to remove rotenone and ensure T cell metabolism was unperturbed. APCs were then pulsed with a peptide derived from the Mycobacterium tuberculosis protein ESAT-6, and co-cultured with ESAT-6-specific CD4+ T cells from a TCR transgenic mouse (112). T cell activation was assayed by intracellular cytokine staining for IFN $\gamma$. In macrophages, T cell stimulation relied on pretreatment of the APC with IFN $\gamma$, as a 
383 macrophage line lacking the Ifngrl gene was unable to support T cell activation. Similarly,

384 inhibition of complex I in macrophages completely abolished antigen-specific T cell stimulation

385 (Figure 7C). DCs did not absolutely require IFN $\gamma$ pretreatment to stimulate T cells, likely due to

386 the basal expression of MHCII by these cells. Regardless, rotenone treatment of DC abrogated

387 the IFN $\gamma$-dependent increase in T cell stimulation (Figure 7C).

To confirm the effects of complex I inhibition on $\mathrm{T}$ cell activation using a genetic

389 approach and confirm that complex I inhibition acted in a cell-autonomous mechanism, we

390 generated Ndufal knockout myeloid progenitors (Hox-sgNdufal). Following differentiation into

391 macrophages, Hox-sgNdufal demonstrated glycolytic dependence and the inability to generate

392 ATP by OXPHOS compared to control Hox-sgNTC macrophages (Supplementary Figure 2G).

393 Having confirmed the expected metabolic effects of Ndufa1 loss, Hox-sgNdufal and Hox-

394 sgNTC macrophages were mixed at various ratios. Mixed cultures were then stimulated with

395 IFN $\gamma$, peptide pulsed, and co-cultured with antigen-specific CD4+ T cells. In agreement with our

396 chemical inhibition studies, we found strong correlation between complex I activity in the APC

397 population and $\mathrm{T}$ cell stimulatory activity (Figure 7D-E). Together, these data confirm that the

398 IFN $\gamma$-dependent augmentation of T cell stimulatory activity depends on complex I function in

399 both macrophages and DCs.

\section{Discussion}

IFN $\gamma$-mediated control of APC function is central to shaping a protective immune

403 response, and the canonical IFN $\gamma$ signal transduction pathway has been elucidated in exquisite

404 detail (113). Our study demonstrates that unbiased genetic analyses can reveal a multitude of 
independently assessing genetic determinants of stimulatory and inhibitory molecule expression, we discovered mechanisms of regulation that preferentially affect the induction of different cell surface proteins. These results begin to explain how a single cytokine can induce functionally distinct downstream responses in different contexts. These data also suggest new strategies to modulate individual co-receptors to either stimulate or inhibit $\mathrm{T}$ cell activation. Another strength

411 of our parallel screen approach was the increased power to identify shared mechanisms that

412 control IFN $\gamma$-mediated regulation across all screens. Our pooled analysis identified

413 mitochondrial respiration, and in particular complex I, as essential for IFN $\gamma$-responses in APCs.

414 We determined that complex I is required for the IFN $\gamma$-mediated induction of key immune

415 molecules and is necessary for antigen presentation and $\mathrm{T}$ cell activation. These findings uncover 416 a new dependency between cellular metabolism and the immune response. necessary for early events in signal transduction from the IFN $\gamma$ receptor complex, and complex I of the respiratory chain is specifically required. While IFN $\gamma$ stimulation has been reported to

420 mediate a reduction in oxygen consumption and a shift to aerobic glycolysis over time (66), the

421 requirement of mitochondrial respiration in IFN $\gamma$ responses has not been assessed previously.

422 Our results indicate that complex I is required for IFN $\gamma$ signaling regardless of these metabolic

423 shifts. Complex I is a metabolic hub with several core functions that cumulatively recycle

424 nicotinamide adenine dinucleotide (NAD+), reduce ubiquinol, and initiate the PMF for ATP

425 generation. While any or all of these physiologic processes could contribute to IFN $\gamma$ signaling,

426 the differential effects of chemical inhibitors narrow the possibilities. Both rotenone and

427 oligomycin inhibit the IFN $\gamma$ response, and block electron flux through complex I either directly

428 or indirectly. In contrast, the ionophore CCCP disrupts the PMF and ATP generation without 
429 inhibiting electron transfer, and does not affect IFN $\gamma$ signaling. These data indicate that the

430 reduction state of the quinone pool and ATP generation do not regulate IFN $\gamma$ responses in our

431 system. Instead, complex I-dependent regeneration of NAD+ is the most likely regulator of IFN $\gamma$

432 signaling. Indeed, NAD+ synthesis via either the de novo or salvage pathway is necessary for a

433 variety of macrophage functions (114-116). Very recent work demonstrates an important role for

434 NAD+ in STAT1 activation and PD-L1 induction by IFN $\gamma$ in hepatocellular carcinoma cells

435 (117). In this setting, inhibition of NAD+ synthesis reduces the abundance of phospho-STAT1

436 by disrupting a direct interaction with the Ten-eleven translocation methylcytosine dioxygenase

4371 (TET1). It remains unclear if a similar interaction occurs in the myeloid cells that are the focus

438 of our work, as TET1 is expressed at very low levels in macrophages and splenic DC (118).

439 Regardless, these observations indicate that both NAD+ synthesis and its regeneration via

440 mitochondrial respiration contribute to the IFN $\gamma$ response in diverse cell types. This recently

441 revealed interaction between metabolism and immunity could contribute to the observed

442 association between NAD+ homeostasis and inflammatory diseases (116), as well as the efficacy

443 of checkpoint inhibitor therapy for cancer (117).

444 In the APC setting, we found that $\mathrm{T}$ cell activation required mitochondrial respiration.

445 While complex I function, MHCII and CD40 expression all largely correlate with T cell

446 stimulation, our data indicate that additional IFN $\gamma$-inducible pathways also contribute to this

447 activity. For example, unstimulated DCs basally express similar levels of MHCII as IFN $\gamma$ -

448 stimulated macrophages but are unable to productively present antigen to $\mathrm{T}$ cells. This

449 observation suggests that additional aspects of antigen processing, presentation, or co-stimulation

450 are IFN $\gamma$ - and complex I-dependent. Similarly, MHCI presentation machinery is transcriptionally

451 induced upon IFN $\gamma$ stimulation $(7,119)$ and the induction of molecules recognized by donor 
452 unrestricted $\mathrm{T}$ cells, such as MR1 and CD1, might also require additional signals to function. The

453 specific effects of mitochondrial respiration on the type and quality of the $\mathrm{T}$ cell response will

454 depend on how these diverse antigen-presenting and co-signaling molecules are influenced by

455 cellular metabolic state.

456 The observation that IFN $\gamma$ signaling depends on mitochondrial respiration provides a

457 stark contrast to the well-established glycolytic dependency of many phagocyte functions, such

458 as TLR signaling. This metabolic dichotomy between proinflammatory TLR signals and the

459 IFN $\gamma$ response mirrors known regulatory interactions between these pathways. For example,

460 TLR stimulation has been shown to inhibit subsequent IFN $\gamma$ responses, via a number of target

461 gene-specific mechanisms (120-124). However, TLR stimulation also results in the disassembly

462 of the ETC $(123,124)$, which our observations predict to inhibit STAT1 phosphorylation and

463 IFN $\gamma$ signaling at the level of the receptor complex. More generally, our work suggests

464 fundamental metabolic programs contribute to the integration of activation signals by APC and

465 influence the ultimate priming of an immune response.

\section{Materials and Methods}

\section{Cell culture}

469 Cells were cultured in Dulbecco's Modified Eagle Medium (Gibco 11965118) supplemented

470 with 10\% fetal bovine serum (Sigma F4135), sodium pyruvate (Gibco 11360119), and HEPES

471 (15630080). Primary bone marrow-derived macrophages (BMDMs) were generated by culturing

472 bone marrow in the presence of media supplemented with $20 \%$ L929 supernatant for 7 days. 
474 Immortalized macrophage cell lines in C57B16/J and Cas9-EGFP were established in using J2

475 retrovirus from supernatant of CREJ2 cells as previously described(125). Briefly, isolated bone

476 marrow was cultured in the presence of media enriched with 20\% L929 supernatant. On day 3 ,

477 Cells were transduced with virus and cultured with virus for 2 days. Over the next 8 weeks, L929

478 media was gradually reduced to establish growth factor independence.

480 Conditionally immortalized myeloid progenitor cell lines were generated by retroviral

481 transduction using an estrogen-dependent Hoxb8 transgene as previously described(110).

482 Briefly, mononuclear cells were purified from murine bone marrow using Ficoll-Paque Plus (GE

483 Healthcare 17144002) and cultured in RPMI (Gibco 11875119) containing 10\% fetal bovine

484 serum (Sigma F4135), sodium pyruvate (Gibco 11360119), and HEPES (15630080), IL-6

485 (10ng/mL; Peprotech \#216-16), IL-3 (10ng/mL; Peprotech \#213-13), and SCF (10ng/mL;

486 Peprotech \#250-03) for 48 hours. Non-adherent bone marrow cells from C57B16/J (Jax 000664),

487 Cas9-EGFP knockin (Jax 026179), or Ifngr1 knockout (Jax 003288) mice were transduced with

488 ER-Hoxb8 retrovirus. After transduction cells were cultured in with media supplemented with

489 supernatant from B16 cells expressing GM-CSF and 10uM estradiol (Sigma E8875) to generate

490 macrophage progenitor cell lines or in media supplemented with supernatant from B16 cells

491 expressing FLT3L and 10uM estradiol (Sigma E8875) to generate dendritic cell progenitor lines.

492 To differentiate macrophages, progenitors were harvested and washed twice with PBS to remove

493 residual estradiol and cultured in L929 supplemented media as above. To differentiate dendritic

494 cells(111), progenitors were harvested, washed 2x with PBS, and cultured in FLT3-enriched

495 complete RPMI for 8-10 days. 
497 Human monocyte-derived macrophages (MDM) were differentiated from mononuclear cells of

498 healthy donors. Briefly, peripheral blood mononuclear cells (PBMCs) were isolated from whole

499 blood using Ficoll-Paque-PLUS (GE Healthcare 17144002). CD14+ monocytes were purified

500 using MojoSort ${ }^{\mathrm{TM}}$ Human CD14 Nanobeads (Biolegend 480093) according to the manufacturer's

501 protocol. Cells were cultured in RPMI with 10\% FBS, sodium pyruvate, and HEPES and

502 supplemented with recombinant GM-CSF (50ng/mL, Peprotech 300-03) for 6 days. Thaws were

503 harvested using Accutase (Gibco A1110501).

\section{Cell stimulations}

506 Murine IFN $\gamma$ (Peprotech 315-05) and human IFN $\gamma($ Peprotech 300-02) were used at 10ng/mL

507 unless otherwise indicated in the figure legends. Murine TNF (315-01A) was used at 25ng/mL.

508 Pam3CSK4 (Invivogen tlrl-pms) was used at 200ng/mL.

510 CRISPR screens

511 A clonal macrophage cell line stably expressing Cas9 (L3) was established as described

512 elsewhere(79). A plasmid library of sgRNAs targeting all protein coding genes in the mouse

513 genome (Brie Knockout library, Addgene 73633) was packaged into lentivirus using HEK293T

514 cells. HEK293T supernatants were collected and clarified, and virus was titered by quantitative

515 real-time PCR and by colony counting after transduction of NIH3T3. L3 cells were transduced at

516 a multiplicity of infection (MOI) of $\sim 0.2$ and selected with puromycin 48 hours after

517 transduction $(2.5 \mathrm{ug} / \mathrm{mL})$. The library was minimally expanded to avoid skewing mutant

518 representation and then frozen in aliquots in freezing media (90\% FBS 10\% DMSO). 
520 Two replicate screens for MHCII, CD40, and PD-L1 were performed as follows:

$5212 \mathrm{e} 8$ cells of the knockout (KO) library was stimulated with IFN $\gamma(10 \mathrm{ng} / \mathrm{mL}$; Peprotech 315-05)

522 for 24 hours after which cells were harvested by scraping to ensure integrity of cell surface

523 proteins. Cell were stained with TruStain FcX anti-mouse CD16/32 (Biolegend 101319) and

524 LIVE/DEAD Fixable Aqua (Invitrogen L34957) per the manufacturer's instructions. For each of

525 the respective screens, stimulated library was stained for its respective marker with the following

526 antibody: MHCII (APC anti-mouse I-A/I-E Antibody, Clone M5/114.15.2 Biolegend 107613),

527 CD40 (APC anti-mouse CD40 Antibody, Clone 3/23 Biolegend 124611), or PD-L1 (APC anti-

528 mouse CD274 (B7-H1, PD-L1) Antibody, Clone 10F.9G2 Biolegend 124311). Each antibody

529 was titrated for optimal staining using the isogenic L3 macrophage cell line. Following staining,

530 cells were fixed in 4\% paraformaldehyde. High and low expressing populations were isolated by

531 fluorescence activated cell sorting (FACS) using a BD FACS Aria II Cell Sorter. Bin size was

532 guided by control cells which were unstimulated and to ensure sufficient library coverage $(>25 \mathrm{x}$

533 unselected library, or $>2 \mathrm{e} 6$ cells per bin). Following isolation of sorted populations,

534 paraformaldehyde crosslinks were reversed by incubation in proteinase K (Qiagen) at 55 degrees

535 for 6-8 hours. Subsequently, genomic DNA was isolated using DNeasy Blood and Tissue Kit

536 (Qiagen 69504) according to the manufacturer's instructions. Amplification of sgRNAs by PCR

537 was performed as previously described $(74,126)$ using Illumina compatible primers from IDT,

538 and amplicons were sequenced on an Illumina NextSeq500. Sequence reads were trimmed to

539 remove adapter sequence and to adjust for staggered forward (p5) primer using Cutadapt v2.9.

540 Raw sgRNA counts for each sorted and unsorted (input library) population was quantified using

541 bowtie2 via MAGeCK to map reads to the sgRNA library index (no mismatch allowed); a

542 sgRNAindex was modified to reflect genes transcribed by our macrophage cell line either basally 
543 or upon stimulation with IFN $\gamma$ as previously published(79). Counts for sgRNAs were median

544 normalized to account for variable sequencing depth.

546 MAGeCK-MLE

547 We used MAGeCK-MLE to test for gene enrichment. Two separate analyses were performed in 548 order to: (1) identify regulators of the IFN $\gamma$ response, and (2) identify specific regulators of each 549 of the screen targets. For both analyses, the baseline samples were the input libraries from each 550 of the replicate screens in order to account for slight variabilities in library distribution for each 551 screen. For (1), the generalized linear model was based on a design matrix that was "marker552 blind" and only considered the bin of origin (i.e. MHCII-low, CD40-low, PD-L1-low v. MHCII553 high, CD40-high, PD-L1-high). For (2), the design matrix was "marker-aware and bin-specific" 554 to test for marker-specific differences (i.e. MHCII-low v. CD40-low v. PD-L1-low); the analysis 555 was performed separately for each bin, low or high expressing mutants, to identify marker556 specific positive and negative regulators, respectively. For each analysis, $\beta$ scores (selection co557 efficient) for each gene were summed across conditions to allow for simultaneous assessment of 558 positive and negative regulators across conditions. Data are provided in Supplementary Tables.

560 Gene-set enrichment analysis (GSEA) was performed using a ranked gene list as calculated from

561 MAGeCK-MLE beta scores and false discovery rate (FDR). To facilitate the identification of

562 positively and negatively enriched gene sets from the high and low expressing populations, the

563 positive ("pos | beta") and negative ("neg | beta") beta scores for each gene were summed as

564 described above ("beta_sum”). To generate a ranked gene list for GSEA, we employed

565 Stouffer's method to sum positive (“pos | z") and negative (“neg | z") selection z-scores, which 
566 were used to re-calculate p-values (“p_sum”) as has been previously described (127-129). Using

567 these summative metrics, we calculated a gene score as: $\log 10\left(\mathrm{p} \_\right.$sum $) *$ (beta_sum). Genes were

568 ranked in descending order and GSEA was performed with standard settings including

569 "weighted" enrichment statistic and "meandiv" normalization mode. Analysis was inclusive of

570 gene sets comprising of 10-500 genes that were compiled and made available online by the

571 Bader lab $(130,131)$.

572

573 Plasmids and sgRNA cloning

574 Lentivirus was generated using HEK293T cells using packaging vector psPAX2

575 (Addgene\#12260) and envelope plasmid encoding VSV-G. Transfections used TransIT-293

576 (MirusBio MIR 2704) and plasmid ratios according to the manufacturer's instructions. For the

577 generation of retrovirus, pCL-Eco in place of separate packaging and envelope plasmid.

578 Retrovirus encoding the ER-Hoxb8 transgene was kindly provided by David Sykes.

580 sgOpti was a gift from Eric Lander \& David Sabatini (Addgene plasmid \#85681)(132).

581 Individual sgRNAs were cloned as previously described. Briefly, annealed oligos containing the

582 sgRNA targeting sequence were phosphorylated and cloned into a dephosphorylated and BsmBI

583 (New England Biolabs) digested SgOpti (Addgene\#85681) which contains a modified sgRNA

584 scaffold for improved sgRNA-Cas9 complexing. Use of sgOpti derivatives for delivery of

585 multiple sgRNAs was performed as detailed elsewhere(79). The sgRNA targeting sequences

586 used for cloning were as follows:

$\begin{array}{ll}\text { Name/Target } & \text { sgRNA sequence } \\ \text { sglfngr1_1 } & \text { TATGTGGAGCATAACCGGAG } \\ \text { sglfngr1_2 } & \text { GGTATTCCCAGCATACGACA } \\ \text { sglrf1_1 } & \text { CTGTAGGTTATACAGATCAG }\end{array}$




$\begin{array}{ll}\text { sglrf1_2 } & \text { CGGAGCTGGGCCATTCACAC } \\ \text { sgPtpn2_1 } & \text { AAGAAGTTACATCTTAACAC } \\ \text { sgPtpn2_2 } & \text { TGCAGTGATCCATTGCAGTG } \\ \text { sgNdufa1_1 } & \text { TGTACGCAGTGGACACCCCG } \\ \text { sgNdufa1_2 } & \text { CGCGTTCCATCAGATACCAC } \\ \text { sgNdufa2_1 } & \text { GCAGGGATTTCATCGTGCAA } \\ \text { sgNdufa2_2 } & \text { ATTCGCGGATCAGAATGGGC } \\ \text { sgStat1_1 } & \text { GGATAGACGCCCAGCCACTG } \\ \text { sgStat1_2 } & \text { TGTGATGTTAGATAAACAGA } \\ \text { sgOstc_1 } & \text { GCGTACACCGTCATAGCCGA } \\ \text { sgOstc_2 } & \text { TCTTACTTCCTCATTACCGG } \\ \text { sgCnbp_1 } & \text { AGGTAAAACCACCTCTGCCG } \\ \text { sgCnbp_2 } & \text { GTTGAAGCCTGCTATAACTG }\end{array}$

588 Flow cytometry

589 Cells were harvested at the indicated times post-IFN $\gamma$ stimulation by scrapping to ensure intact

590 surface proteins. Cells were pelleted and washed with PBS before staining with TruStain FcX

591 anti-mouse CD16/32 (Biolegend 101319) or TruStain FcX anti-human (Biolegend 422301) and

592 LIVE/DEAD Fixable Aqua (Invitrogen L34957) per the manufacturer's instructions. The

593 following antibodies were used as indicated in the figure legends:

594 APC-Fire750 anti-mouse I-A/I-E Antibody, Clone M5/114.15.2 Biolegend 107651

595 PE anti-mouse CD40 Antibody, Clone 3/23 Biolegend 124609

596 Brilliant Violet 421 $1^{\mathrm{TM}}$ anti-mouse CD274 (B7-H1, PD-L1) Antibody, Clone 10F.9G2 Biolegend $597 \quad 124315$

598 Alexa Fluor ${ }^{\circledR} 647$ anti-human CD54 Antibody, Clone HCD54, Biolegned 322718

599 PE anti-human CD40 Antibody, Clone 5C3, Biolegned 334307

600 Brilliant Violet 421 $1^{\mathrm{TM}}$ anti-human CD274 (B7-H1, PD-L1) Antibody, Clone 29E.2A3, Biolegend

$601 \quad 329713$

602 APC/Fire 7 TM 750 anti-human HLA-DR Antibody, Clone L243, Biolegend 307657 
604 For intracellular cytokine staining, cells were treated with brefeldin A (Biolegend 420601) for 5

605 hours before harvesting. Following staining and fixation, cells were permeabilized (Biolegend

606 421002) and stained according to the manufacturer's protocol using the following antibodies:

607 PE anti-mouse IFN- $\gamma$ Antibody, Biolegend 505807

608

609 Surface protein expression was analyzed on either a MacsQuant Analyzer or Cytek Aurora. All

610 flow cytometry analysis was done in FlowJo V10 (TreeStar).

\section{Chemical inhibitors}

613 All chemical inhibitors were used for the duration of cell stimulation unless otherwise stated.

614 Rotenone (Sigma R8875) was resuspended in DMSO and used at 10uM unless indicated

615 otherwise in the figure legend. Oligomycin (Cayman 11342) was resuspended in DMSO and

616 used at 2.5uM unless otherwise indicated. CCCP (Cayman 25458) was resuspended in DMSO

617 and used at 1.5uM unless indicated otherwise. 1400W hydrochloride (Cayman 81520) was

618 resuspended in culture media, filter sterilized and used immediately at 25uM unless otherwise

619 indicated. N-acetyl-L-Cysteine (NAC, Cayman 20261) was resuspended in culture media, filter

620 sterilized and used immediately at 10mM. DMOG (Cayman 71210) was resuspended in DMSO

621 and used at 200uM. UK5099 (Cayman 16980) was resuspended in DMSO and used at 20uM. 2-

622 deoxy-D-Glucose (2DG, Cayman 14325) was resuspended in culture media, filter sterilized and

623 used at $1 \mathrm{mM}$ or at the indicated concentrations immediately. MitoTEMPO hydrate (Cayman

624 16621) was resuspended in DMSO and used at the indicated concentrations. 
626 For experiments that used defined minimal media with carbon supplementation, D-galactose,

627 sodium pyruvate, and D-glucose were used at 10mM in DMEM without any carbon (Gibco

628 A1443001). For establishment of macrophage cell line with diminished mitochondrial mass,

629 cells were continuously cultured in linezolid (LZD) (Kind gift from Clifton Barry) for 4 weeks at

$63050 \mu \mathrm{g} / \mathrm{mL}$ or DMSO control. Both LZD-conditioned and DMSO control lines were

631 supplemented with uridine at $50 \mu \mathrm{g} / \mathrm{mL}$. Prior to experimentation, cells were washed with PBS

632 and cultured without linezolid for at least 12 hours.

633

\section{ELISA and nitric oxide quantification}

635 The following kits were purchased from R and D Systems or Biolegend for quantifying protein

636 for cell supernatants:

637 Mouse IL-6 DuoSet ELISA (DY406) or Biolegend ELISAmax (431301)

638 Mouse TNF-alpha DuoSet ELISA (DY410) or Biolegend ELISAmax (430901)

639 Mouse IFN-gamma DuoSet ELISA (DY485)

640 Human IL-1 beta/IL-1F2 DuoSet ELISA (DY201)

641 Human TNF-alpha DuoSet ELISA (DY210)

642 Nitric oxide was quantified from cell supernatants using the Griess Reagent System according to

643 the manufacturer's instructions (Promega G2930). For these experiments, cell culture media

644 without phenol red (Gibco A1443001 or Gibco 31053028).

645

647 To isolate RNA, cells were lysed in TRIzol (15596026) according to manufacturer's instructions.

648 Chloroform was added to lysis at ratio of 200uL chloroform per $1 \mathrm{~mL}$ TRIzol and centrifuged at 
$12,000 \mathrm{x} g$ for 20 minutes at $4 \mathrm{C}$. The aqueous layer was separated and added to equal volume of

$650100 \%$ ethanol. RNA was isolated using the Zymo Research Direct-zol RNA extraction kit.

651 Quantity and purity of the RNA was checked using a NanoDrop and diluted to 5ng/uL in

652 nuclease-free water before use. Quantitative real-time PCR was performed using NEB Luna®

653 Universal One-Step RT-qPCR Kit (E3005) or the Quantitect SYBR green RT-PCR kit (204243)

654 according to the manufacturer's protocol and run on a Viia7 thermocycler or StepOne Plus

655 Theromocycler. Relative gene expression was determined with ddCT method with beta-Actin

656 transcript as the reference.

\section{Primer}

RT_Actb-1F

RT_Actb-1R

RT_Cd274-1F

RT_Cd274-1R

RT-Ciita-1F

RT-Ciita-1R

RT-Gapdh-1F

RT-Gapdh-1R

\section{Sequence}

GGCTGTATTCCCCTCCATCG

CCAGTTGGTAACAATGCCATGT

GCTCCAAAGGACTTGTACGTG

TGATCTGAAGGGCAGCATTTC

AGACCTGGATCGTCTCGT

AGTGCATGATTTGAGCGTCTC

TGGCCTTCCGTGTTCCTAC

GAGTTGCTGTTGAAGTCGCA

\section{Quantification of mitochondrial genomes}

659 Genomic DNA was isolated from cell pellets using the DNeasy Blood and Tissue Kit (Qiagen

660 69504). Quantitative PCR was run using NEB Luna ${ }^{\circledR}$ Universal One-Step RT-qPCR without the

661 RT enzyme mix and run on a Viia7 thermocycler. Relative quantification of mitochondrial

662 genomes was determined by measuring the relative abundance of mitochondrially encoded gene

$663 \mathrm{Nd} 1$ to the abundance of nuclear encoded $\mathrm{Hk} 2$ as has been described elsewhere(133). All primers

664 are detailed in attached table. 


\author{
Name/Target Sequence \\ Mm-Nd1-1F CTAGCAGAAACAAACCGGGC \\ Mm-Nd1-1R CCGGCTGCGTATTCTACGTT \\ Mm-Hk2-1F GCCAGCCTCTCCTGATTTTAGTGT \\ Mm-Hk2-1R GGGAACACAAAAGACCTCTTCTGG
}

667 Immunoblot

668 At the indicated times following stimulation, cells were washed with PBS once and lysed in on

669 ice using the following buffer: $1 \%$ Triton X-100, 150mM NaCl, 5mM KCl, 2mM MgCl2, $1 \mathrm{mM}$

670 EDTA, 0.1\% SDS, 0.5\% DOC, 25mM Tris-HCl, $\mathrm{pH} 7.4$, with protease and phosphatase inhibitor

671 (Sigma \#11873580001 and Sigma P5726). Lysates were further homogenized using a 25g needle

672 and cleared by centrifugation before quantification (Pierce ${ }^{\mathrm{TM}}$ BCA Protein Assay Kit, 23225).

673 Parallel blots were run with the same samples, 15 ug per well. The following antibodies were

674 used according to the manufacturer's instructions:

675 Purified anti-STAT1 Antibody Biolegend Clone A15158C

676 Purified anti-STAT1 Phospho (Ser727) Antibody, Biolegend Clone A15158B

677 Phospho-Stat1 (Tyr701) Rabbit mAb, Cell Signaling Technology Clone 58D6

678 Jak2 XP® Rabbit mAb, Cell Signaling Technology Clone D2E12

679 Phospho-Jak2 (Tyr1007/1008) Antibody, Cell Signaling Technology \#3771S

680 Anti-mouse $\beta$-Actin Antibody, Santa Cruz Biotechnology Clone C4

681 Biotin anti-mouse CD119 (IFN- $\gamma$ R $\alpha$ chain) Antibody, Biolegend Clone 2E2

682 Goat anti-Rabbit IgG (H+L) Secondary Antibody, HRP, Invitrogen 31460

683 Goat anti-Mouse IgG $(\mathrm{H}+\mathrm{L})$ Secondary Antibody, HRP, Invitrogen 31430

684 HRP-Conjugated Streptavidin, Thermo Scientific N100 


\section{Bioenergetics Assay}

687 Relative glycolytic and respiratory capacity were determined as has previously been

688 demonstrated(134). Briefly, cellular ATP levels were determined using CellTiter-Glo® 2.0 Cell

689 Viability Assay (Promega G9241) according to the manufacturer's protocol. Cells were grown in

690 the conditions indicated in the figure legends for 4 hours unless stated otherwise. ATP levels

691 were normalized according to the figure legend.

692

\section{T cell activation assay}

694 We used a previously established co-culture system to assess antigen presentation to Ag-specific

695 T cells. Briefly, C7 CD4+ T cells were isolated from transgenic C7 mice, respectively and

696 stimulated in vitro with irradiated splenocytes pulsed with the ESAT-61-15 peptide, in complete

697 media (RPMI with 10\% FBS) containing IL-2 and IL-7. After the initial stimulation, the T cells

698 were split every two days for 3-4 divisions and rested for two to three weeks. After the initial

699 stimulation, the cells were cultured in complete media containing IL-2 and IL-7. The following

700 synthetic peptide epitopes were used as antigens from New England Peptide (Gardener, MA):

701 ESAT-61-15 (MTEQQWNFAGIEAAA).

702 For use in co-culture assay, T cells were added to peptide-pulsed macrophages as described in

703 figure legends at an effector to target ratio of 1:1. Following 1 hours of co-culture, brefeldin A

704 was added for 5 hours before assessing intracellular cytokine production by ICS.

705

\section{Quantification of subunit effects on N-module}

707 We used publicly available proteomics data in which the protein abundance of all complex I

708 subunit was measured when each subunit was genetically deleted(93). As determined empirically 
709 by the authors, the N-module components included: NDUFA1, NDUFA2, NDUFS1, NDUFV2,

710 NDUFA6, NDUFS6, NDUFA7, NDUFS4, and NDUFV3. The relative effect of each subunit

711 (using a knockout of that subunit) on N-module protein stability was calculated as the sum of the

712 median $\log 2$ ratio of each of the above mentioned subunits, minus the median $\log 2$ ratio of itself

713 (since it is knocked out).

714

\section{Statistical Analysis and Figures}

716 Statistical analysis was done using Prism Version 8 (GraphPad) as indicated in the figure

717 legends. Data are presented, unless otherwise indicated, as the mean $+/-$ the standard deviation.

718 Figures were created in Prism V8 or R (Version 3.6.2). MAGeCK-MLE was used as part of

719 MAGeCK-FLUTE package v1.8.0. 


\section{Acknowledgements}

722 We thank all the members of the Sassetti, Behar, and Olive labs for critical feedback and input

723 throughout the project. A special thank you to Megan K. Proulx, Mario Meza Segura and the

724 donors for their assistance and expertise to the human macrophage derivation We thank the flow

725 cytometry core at UMMS for their help in all experiments requiring flow cytometry. This work

726 was supported by startup funding to AJO provided by Michigan State University, support from

727 the Arnold O. Beckman Postdoctoral fellowship to AJO and grants from the NIH (AI146504,

728 AI132130), DOD (W81XWH2010147), and USDA (NIFA HATCH 1019371). All data is being

729 deposited into the appropriate databases and is available upon request.

730

\section{Competing Interests}

732 The authors have no competing interests related to the research described in this manuscript. 


\section{Figure Legends:}

\section{Figure 1. Forward genetic screen to identify regulators of the IFN $\gamma$ response. A)}

736 Representative histograms of the three selected cell surface markers targeted in macrophage

737 CRISPR screens: MHCII, CD40, and PD-L1. Blue histograms indicate expression of each

738 marker in unstimulated macrophages and alternatively colored histograms show expression

739 following 24 hour stimulation with recombinant murine IFN $\gamma(10 \mathrm{ng} / \mathrm{mL})$. Gates used for sorting

740 "high" and "low" populations are shown. B) Schematic of CRISPR screens. C) Relative

741 enrichment of select positive control (points) and all 1000 non-targeting control sgRNAs (gray

742 distribution) are plotted as a function of their log2 fold enrichment ("high" vs "low" bins). Data

743 are from both replicate selections for each sgRNA (sgRNA denoted by shape). D) Heatmap of $\beta$

744 scores from CRISPR analysis, ordered according to k-means clustering $(\mathrm{k}=8)$ of the $5 \%$ most

745 enriched or depleted genes in each screen. E) Macrophages were stimulated for 24 hours with

746 TNF (25ng/mL), IFN $\gamma(10 \mathrm{ng} / \mathrm{mL})$ or both TNF and IFN $\gamma$. Mean fluorescence intensity (MFI) of

747 CD40 and MHCII were quantified by flow cytometry. Data are mean \pm the standard deviation for

7483 biological replicates. Representative scatter plot from two independent experiments is

749 provided. F) Macrophages transduced with sgRNA targeting Stat1, Ostc, Cnbp, or a NTC control

750 were cultured with or without IFN $\gamma$ for 24 hours and cell surface expression of PD-L1 (MFI) was

751 quantified by flow cytometry. For each genotype, data are the mean of cell lines with two

752 independent sgRNAs \pm the standard deviation. Data are representative of three independent

753 experiments. Statistical testing in panel C was performed with Tukey's multiple comparisons

754 test. Within each screen, the sgRNA effects for each gene were compared to the distribution non-

755 targeting control sgRNAs. Statistical testing in panels E and F was performed by one-way 
ANOVA with Holm-Sidak multiple comparisons correction. p values of $0.05,0.01,0.001$, and 0.001 are indicated by $*, * *, * * *$, and $* * * *$

Figure 2. Global analysis of knockout libraries implicates mitochondrial complex I is a

positive regulator of the IFN $\gamma$ response. A) Rank plot of the combined analysis for all genome-

wide knockout screens. Gene ranks (x-axis) were determined by maximal likelihood estimation

(MLE). Known positive (left) and negative (right) regulators of IFN $\gamma$-mediated signaling are

FDR). B). Gene set enrichment analysis (GSEA) is based on the ranked list of positive

regulators. Non-redundant pathways with a normalized enrichment score (NES) exceeding 2.0

and a false discovery rate (FDR) below 0.025 are labeled. C) Relative enrichment ( $\log 2$ fold change between "high" and "low" bins) of genes which comprise the mitochondrial respirasome statistical enrichment of a gene (e.g. Ndufal) or module (e.g. N) was calculated using a binomial

772 distribution function to calculate the probability that observed sgRNAs under examination would

773 be depleted or enriched given the expected median probability. P values of $0.05,0.01,0.001$, and

7740.001 are indicated by $*, * *, * * *$, and $* * * *$. E) Correlation between the relative effect of each

775 complex I subunit on the structural integrity of the N-module (x-axis) with the relative

776 requirement of each complex I subunit for the IFN $\gamma$-response (y-axis; $\beta$ score, as in Panel D).

777 The Pearson correlation coefficient (r) was calculated to be 0.6452 (95\% confidence interval

$778 \quad 0.3584$ to $0.8207 ; \mathrm{p}$-value $=0.0002$. As $N d u f a b 1$ (empty square) is an essential gene, its 
779 detection in the library indicates editing did not eliminate function; therefore, it was excluded

780 from correlation analysis.

Figure 3. Complex I is necessary for IFN $\gamma$-induced MHCII and PD-L1 expression.

783 Metabolic phenotypes in macrophage mutants were confirmed using ATP abundance following

784 culture in media containing only (A) glucose or (B) pyruvate. Values are normalized to the average respiratory capacity of non-targeting control macrophages (NTC) and are the mean \pm the standard deviation for 4 biological replicates. Statistical testing within each condition (with or without IFN $\gamma$ for 24h) was performed by one-way ANOVA with Dunnett's multiple comparisons correction. (C-F) Non-targeting control (NTC), positive control (sgIfngrl and sgPtpn2) and

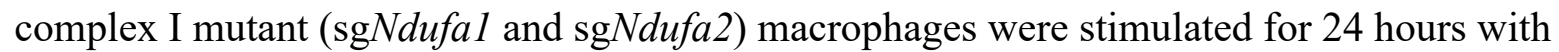
recombinant murine IFN $\gamma$. Plotted values in $\mathrm{C}$ and $\mathrm{E}$ are the geometric mean fluorescence intensity (MFI) for a given mutant normalized to an internal control present in each well; for

792 each gene, the data are the mean for two independent $\operatorname{sgRNAs} \pm$ the standard deviation.

793 Representative histograms are provided in D and F. Data are representative of $>5$ independent experiments. G) MHCII MFI of macrophages stimulated with IFN $\gamma$ and treated with rotenone at the indicated concentrations for 24 hours. Mean \pm the standard deviation for 2 biological replicates are shown. Data are representative of four independent experiments. H) Left: MHCII

797 MFI on macrophages cultured in complete media (CM) and stimulated with IFN $\gamma$ and the 798 indicated inhibitors for 24 hours. Right: MHCII MFI on macrophages cultured in CM or media 799 containing only pyruvate (Pyr) or citrate (Cit) with or without UK5099 and stimulated with 800 IFN $\gamma$ for 24 hours. Mean \pm standard deviation for 2 or 3 biological replicates is indicated. Data 801 are representative of four independent experiments. Statistical testing was performed by one-way 
ANOVA with Tukey correction for multiple hypothesis testing. $p$ values of $0.05,0.01,0.001$, and 0.001 are indicated by $*, * *, * * *$, and $* * * *$.

Figure 4. Diminished mitochondrial function specifically limits IFN $\gamma$-dependent responses.

A) TNF and IL-6 production by NTC or complex I mutant macrophages stimulated with

Pam3CSK 4 for 24 hours was determined by ELISA. Statistical testing between mutant and NTC macrophages from triplicate samples was performed by ANOVA with Dunnett's correction for multiple comparisons. Data are representative of two independent experiments. B) qPCR determination of relative mitochondrial genomes present per nuclear genome in macrophages

811 cultured in vehicle (WT) or $50 \mathrm{ug} / \mathrm{mL}$ linezolid (LZD). $\mathrm{C}_{\mathrm{t}}$ values were normalized to reference 812 nuclear gene hexokinase $2(H k 2)$ and plotted as abundance relative to WT. Data were analyzed

813 by two-way unpaired t-test. C) ATP abundance in control or LZD-conditioned macrophages

814 cultured in $10 \mathrm{mM}$ glucose, galactose or pyruvate. ATP values normalized to mean of $10 \mathrm{mM}$

815 glucose and plotted as percent. Mean \pm the standard deviation for 2 biological replicates of each condition. Differences were tested by two-way ANOVA using the Sidak method to correct for multiple hypothesis testing. D) MFI of MHCII was determined by flow cytometry on control or LZD-conditioned macrophages following 24 hour stimulation with IFN $\gamma$. Mean \pm the standard

819 deviation for 2 biological replicates of each condition and representative of two independent experiments. Differences were tested by two-way ANOVA using the Tukey method to correct

821 for multiple hypothesis testing. E and F) Secretion of TNF and IL-6 in WT and LZD-conditioned macrophages following Pam3CSK4 stimulation for 6 hours was quantified by ELISA. Mean \pm

823 the standard deviation for 3 biological replicates of each condition and two independent 
bioRxiv preprint doi: https://doi.org/10.1101/2020.11.22 393538; this version posted November 23, 2020. The copyright holder for this preprint (which was not certified by peer review) is the author/funder, who has granted bioRxiv a license to display the preprint in perpetuity. It is made available under aCC-BY-ND 4.0 International license.

824 experiments. Data were analyzed by two-way unpaired t-test. p values of $0.05,0.01,0.001$, and

8250.001 are indicated by $*, * *, * * *$, and $* * * *$.

826 
827 Figure 5. Complex I is specifically required for IFN $\gamma$ signaling in human cells. A) CD14+

828 monocytes from healthy human donors were differentiated into macrophages. MFI of cell

829 surface markers PD-L1, ICAM1, CD40 and HLA-DR was determined by flow cytometry

830 following stimulation with IFN $\gamma$ and/or inhibition of complex I with rotenone (10uM) for 24

831 hours. Data are representative of two independent experiments and values are normalized to

832 donor-specific unstimulated/vehicle control. Mean \pm the standard deviation for 6 biological

833 replicates of each condition. Differences were tested by two-way ANOVA using the Sidak-Holm

834 method to correct for multiple hypothesis testing. B and C) Quantification of IL-1B and TNF

835 production from primary human macrophages, measured by ELISA from cell supernatants

836 following stimulation. Lines connect values for individual donors treated with vehicle (DMSO,

837 black squares) or rotenone (empty squares). Differences were tested by repeat-measure two-way

838 ANOVA using the Sidak-Holm method to correct for multiple hypothesis testing. p values of

$8390.05,0.01,0.001$, and 0.001 are indicated by $*, * *, * * *$, and $* * * *$. 
Figure 6. Complex I inhibition reduces IFN $\gamma$ receptor activity. A) PD-L1 transcript was

841 quantified by qRT-PCR using $\Delta \Delta \mathrm{Ct}$ relative to $\beta$-Actin in macrophages of the indicated genotype

842 after stimulation with $10 \mathrm{ng} / \mathrm{mL}$ IFN $\gamma$. PD-L1 MFI was determined at the same time points by

843 flow cytometry. B) Ciita transcript was quantified by qRT-PCR using $\Delta \Delta \mathrm{Ct}$ relative to $\beta$-Actin

844 Gapdh in macrophages of the indicated genotype after stimulation with $10 \mathrm{ng} / \mathrm{mL}$ IFN $\gamma$. MHCII

845 MFI was determined at the same time points by flow cytometry. Data shown are from biological

846 triplicate samples with technical replicates for RT-PCR experiments and are representative of

847 two independent experiments. C) sgNTC (left) or sgIrfl (right) macrophages were cultured for

84824 hours with or without IFN $\gamma$ stimulation. At 2 hour intervals post-IFN $\gamma$ stimulation, rotenone

849 was added. After 24 hours of stimulation, cells were harvested and surface expression of MHCII

850 (MFI) was quantified by flow cytometry. Data are mean \pm the standard deviation for 3 biological

851 replicates and are representative of two independent experiments. Statistical testing was

852 performed by one-way ANOVA with Tukey correction for multiple hypothesis testing. D)

853 Control (NTC) or $\operatorname{sgNdufal~macrophages~were~stimulated~with~IFN~} \gamma$ for the indicated times, and

854 cell lysates analyzed by immunoblot for STAT1 abundance and phosphorylation (Y701 and

855 S727), JAK2 abundance and phosphorylation (Y1007/8), and IFNGR1. Beta-Actin was used as a

856 loading control. Data are representative of three independent experiments. Results shown are

857 from a single experiment analyzed on three parallel blots. $p$ values of $0.05,0.01,0.001$, and

$858 \quad 0.001$ are indicated by $*, * *, * * *$, and $* * * *$.

860 Figure 7. Mitochondrial respiration in antigen presenting cells is required IFN $\boldsymbol{\gamma}$-dependent

861 T cell activation. A) Cell surface expression of MHCII (MFI) in macrophages (MF) or dendritic

862 cells (DC) derived from conditionally immortalized progenitor lines. IFN $\gamma$ was added for 24 
863 hours where indicated. Cells were treated with vehicle (DMSO), rotenone (10uM), oligomycin

864 (OM, 2.5uM), or CCCP concurrent with IFN $\gamma$. Data are three biological replicates and are

865 representative of at least two independent experiments. B) Contour plot of macrophage (top row)

866 or dendritic cell (bottom row) MHCII expression in the absence of (left column) or following

867 (right column) stimulation with IFN $\gamma$ for 24 hours. Representative samples were selected from

868 (A). The percent MHCII positive are indicated for each of the conditions. C) CD4+ T cell

869 activation as measured by the percent of live cells positive for IFN $\gamma$ by intracellular cytokine

870 staining. Prior to co-culture with T cells, APCs were stimulated with the indicated combinations

871 of IFN $\gamma(10 \mathrm{ng} / \mathrm{mL})$, and/or rotenone $(10 \mathrm{uM})$ for 24 hours. After washing and pulsing with

872 ESAT-61-15 at the indicated concentrations (nm.), T cells were added to APCs at an effector to

873 target (E:T) ratio of 1:1, and co-cultured for a total of 5 hours. Data are representative of two

874 independent experiments. Data are mean \pm the standard deviation for 3 biological replicates.

875 Statistical testing was performed by one-way ANOVA with Tukey correction for multiple

876 hypothesis testing. D and E) sgNdufal or NTC macrophages were differentiated from

877 immortalized progenitors, and mixed at the ratios indicated (labeled as percent of KO cells).

878 Mixed cultures were stimulated with IFN $\gamma$ for 24 hours, peptide loaded, and co-cultured with

879 CD4+ T cells (E:T 1:1). Production of IFN $\gamma$ was measured by ICS and quantified as the percent

880 of cells positive for staining by flow cytometry. Representative contour plots (D) and

881 quantification (E) of the experiment are shown. Data shown are for biological triplicate samples

882 and are representative of two independent experiments. p values of $0.05,0.01,0.001$, and 
Supplementary Figure Legends:

887 Figure S1, Related to Figure 3. A) sgNTC, sgNdufal, sgNdufa2 cells cultured in complete media and treated with or without oligomycin $(2.5 \mu \mathrm{M})$ for 4 hours. Relative ATP levels were determined as in Figure 2A B) Intracellular ATP levels quantified as relative light units (RLU) using CellTiterGlo2.0 (Promega) for macrophages in specified growth conditions for 4 hours.

891 Concentrations of carbon source and inhibitors are indicated in Materials and Methods. C) Macrophages were cultured in either glucose or galactose and stimulated with IFN $\gamma$ for 24 hours.

893 Following stimulation, the proportion of cells with MHCII expression was determined by flow cytometry. D) Macrophages were cultured in conditions as described in Figure 4H. For each

895 condition, cells were stimulated with IFN $\gamma$ or IFN $\gamma$ and N-acetylcysteine (NAC) for 24 hours 896 after which cell surface levels of MHCII were quantified. E) Control or complex I mutant 897 ( $\operatorname{sgNdufa2)~macrophages~were~stimulated~with~IFN~} \gamma$ for 24 hours with increasing doses of mitochondrial reactive oxygen species scavenger MitoTempo. For each concentration, values are

899 plotted as a fold change relative to no scavenger; Mean \pm the standard deviation for 2 biological

900 replicates of each condition. F) Control or complex I deficient macrophages were stimulated

901 with IFN $\gamma$ for 24 hours with or without the addition of DMOG or 1400W. Following stimulation,

902 the proportion of cells with MHCII expression was determined by flow cytometry. G) Nitric

903 oxide was measured using Griess Reagent System (Promega) from cell supernatants following

904 stimulation with IFN $\gamma$ and Pam3CSK4 for 24 hours with or without the addition of DMOG or

905 1400W. Relative nitric oxide levels were calculated as a percent relative to control (IFN $\gamma$ and

906 Pam3CSK4 with DMSO). All data are representative of at least two independent experiments. 
907 Statistical testing was performed using one-way ANOVA with Holm-Sidak multiple comparison

908 correction. $\mathrm{p}$ values of $0.05,0.01,0.001$, and 0.001 are indicated by $*, * *, * * *$, and $* * * *$.

911 Figure S2, Related to Figure 7. A-C) Myeloid progenitors cells were conditionally

912 immortalized by transducing murine bone marrow with an estrogen-dependent Hoxb8 transgene

913 which maintains stem-like properties. Following differentiation of progenitors into macrophages

914 using M-CSF enriched conditioned media, macrophages were stimulated with IFN $\gamma$ with or

915 without rotenone. 24 hours after stimulation, cell surface levels of (A) MHCII, (B) CD40, (C)

916 and PD-L1 were quantified by flow cytometry. Data are representative of 3 independent

917 experiments and are the mean \pm the standard deviation for 2 biological replicates. Statistical

918 testing was performed by one-way ANOVA with Tukey correction for multiple hypothesis

919 testing. D-F) As in panels A-C, macrophages from either immortalized macrophage progenitors

920 or primary bone marrow were stimulated with IFN $\gamma$ with or without rotenone or oligomycin. 24

921 hours after stimulation, cell surface levels of (D) MHCII, (E) CD40, (F) and PD-L1 were

922 quantified by flow cytometry. G). Wild-type or $\Delta$ Ndufal macrophages derived from Hoxb8-

923 immortalized bone marrow progenitors were cultured in the specified media and inhibitor

924 condition before total intracellular ATP was quantified by CellTiterGlo2.0. For each genotype,

925 values are relative to "glucose" control. Mean \pm the standard deviation for 2 biological replicates

926 of each condition. p values of $0.05,0.01,0.001$, and 0.001 are indicated by $*, * *, * * *$, and $* * * *$. 
bioRxiv preprint doi: https://doi.org/10.1101/2020.11.22.393538; this version posted November 23, 2020. The copyright holder for this preprint (which was not certified by peer review) is the author/funder, who has granted bioRxiv a license to display the preprint in perpetuity. It is made available under aCC-BY-ND 4.0 International license.

\section{1}




\section{Bibliography}

934 1. Mechanisms of costimulation, (2009).

935 2. Attanasio J, Wherry EJ. Costimulatory and Coinhibitory Receptor Pathways in Infectious Disease. Immunity. 2016;44(5):1052-68. Epub 2016/05/19. doi:

3. Genetic control of MHC class II expression, (2002).

4. Buxadé M, Encabo HH, Riera-Borrull M, Quintana-Gallardo L, López-Cotarelo P, Tellechea M, Martínez-Martínez S, Redondo JM, Martín-Caballero J, Flores JM, Bosch E, Rodríguez-Fernández JL, Aramburu J, López-Rodríguez C. Macrophage-specific MHCII expression is regulated by a remote Ciita enhancer controlled by NFAT5. Journal of Experimental Medicine. 2018. doi: 10.1084/jem.20180314. PubMed PMID: 30327417.

5. Herrero C, Marqués L, Lloberas J, Celada A. IFN- $\gamma$-dependent transcription of MHC class II IA is impaired in macrophages from aged mice. Journal of Clinical Investigation. 2001. doi: 10.1172/JCI11696. PubMed PMID: 11181648.

6. Regulation of MHC class II gene expression by the class II transactivator, (2005).

7. Present Yourself! By MHC Class I and MHC Class II Molecules, (2016).

8. Steimle V, Siegrist CA, Mottet A, Lisowska-Grospierre B, Mach B. Regulation of MHC class II expression by interferon- $\gamma$ mediated by the transactivator gene CIITA. Science. 1994. doi: 10.1126/science.8016643. PubMed PMID: 8016643.

9. Wheelock EF. Interferon-Like Virus-Inhibitor Induced in Human Leukocytes by Phytohemagglutinin. Science. 1965;149(3681):310-1. Epub 1965/07/16. doi: 10.1126/science.149.3681.310. PubMed PMID: 17838106.

10. Tominaga K, Yoshimoto T, Torigoe K, Kurimoto M, Matsui K, Hada T, Okamura H, Nakanishi K. IL-12 synergizes with IL-18 or IL-1beta for IFN-gamma production from human T cells. Int Immunol. 2000;12(2):151-60. Epub 2000/02/02. doi: 10.1093/intimm/12.2.151. PubMed PMID: 10653850.

11. O'Shea JJ, Paul WE. Regulation of T(H)1 differentiation--controlling the controllers. Nat Immunol. 2002;3(6):506-8. Epub 2002/05/29. doi: 10.1038/ni0602-506. PubMed PMID: 12032561.

12. Schneider BE, Korbel D, Hagens K, Koch M, Raupach B, Enders J, Kaufmann SHE, Mittrücker HW, Schaible UE. A role for IL-18 in protective immunity against Mycobacterium tuberculosis. European Journal of Immunology. 2010. doi: 10.1002/eji.200939583.

13. Interleukin-12 and the regulation of innate resistance and adaptive immunity, (2003).

14. Johnson-Léger C, Hasbold J, Holman M, Klaus GG. The effects of IFN-gamma on CD40mediated activation of B cells from X-linked immunodeficient or normal mice. The Journal of Immunology. 1997;159:1150-9.

15. Alderson MR, Armitage RJ, Tough TW, Strockbine L, Fanslow WC, Spriggs MK. CD40 expression by human monocytes: regulation by cytokines and activation of monocytes by the ligand for CD40. Journal of Experimental Medicine. 1993;178(2):669-74. doi: 10.1084/jem.178.2.669.

16. Yamazaki T, Akiba H, Iwai H, Matsuda H, Aoki M, Tanno Y, Shin T, Tsuchiya H, Pardoll DM, Okumura K, Azuma M, Yagita H. Expression of programmed death 1 ligands by 
murine T cells and APC. J Immunol. 2002;169(10):5538-45. Epub 2002/11/08. doi: 10.4049/jimmunol.169.10.5538. PubMed PMID: 12421930.

17. Cross-regulation of Signaling Pathways by Interferon- $\gamma$ : Implications for Immune Responses and Autoimmune Diseases, (2009).

18. Krawczyk CM, Holowka T, Sun J, Blagih J, Amiel E, DeBerardinis RJ, Cross JR, Jung E, Thompson CB, Jones RG, Pearce EJ. Toll-like receptor-induced changes in glycolytic metabolism regulate dendritic cell activation. Blood. 2010. doi: 10.1182/blood-2009-10249540. PubMed PMID: 20351312.

19. Liu P-S, Wang H, Li X, Chao T, Teav T, Christen S, Di Conza G, Cheng W-C, Chou C-H, Vavakova M, Muret C, Debackere K, Mazzone M, Huang H-D, Fendt S-M, Ivanisevic J, Ho P-C. a-ketoglutarate orchestrates macrophage activation through metabolic and epigenetic reprogramming. nature immunology. 2017;18. doi: 10.1038/ni.3796.

20. The role of B7 co-stimulation in activation and differentiation of CD4+ and CD8+ T cells, (1998).

21. Nau GJ, Richmond JFL, Schlesinger A, Jennings EG, Lander ES, Young RA. Human macrophage activation programs induced by bacterial pathogens. Proceedings of the National Academy of Sciences of the United States of America. 2002;99:1503-8. doi: 10.1073/pnas.022649799. PubMed PMID: 11805289.

22. Schnare M, Barton GM, Holt AC, Takeda K, Akira S, Medzhitov R. Toll-like receptors control activation of adaptive immune responses. Nature Immunology. 2001. doi: 10.1038/ni712. PubMed PMID: 11547333.

23. Francisco LM, Sage PT, Sharpe AH. The PD-1 pathway in tolerance and autoimmunity. Immunol Rev. 2010;236:219-42. Epub 2010/07/20. doi: 10.1111/j.1600065X.2010.00923.x. PubMed PMID: 20636820; PMCID: PMC2919275.

24. Dendritic cells giveth and taketh away, (2005).

25. Brown JA, Dorfman DM, Ma F-R, Sullivan EL, Munoz O, Wood CR, Greenfield EA, Freeman GJ. Blockade of Programmed Death-1 Ligands on Dendritic Cells Enhances T Cell Activation and Cytokine Production. The Journal of Immunology. 2003;170:1257-66. doi: 10.4049/jimmunol.170.3.1257.

26. Schildberg FA, Klein SR, Freeman GJ, Sharpe AH. Coinhibitory Pathways in the B7-CD28 Ligand-Receptor Family. Immunity. 2016;44(5):955-72. Epub 2016/05/19. doi: 10.1016/j.immuni.2016.05.002. PubMed PMID: 27192563; PMCID: PMC4905708.

27. Bousoik E, Montazeri Aliabadi H. "Do We Know Jack" About JAK? A Closer Look at JAK/STAT Signaling Pathway. Frontiers in Oncology. 2018. doi: 10.3389/fonc.2018.00287.

28. Garcia-Diaz A, Shin DS, Moreno BH, Saco J, Escuin-Ordinas H, Rodriguez GA, Zaretsky JM, Sun L, Hugo W, Wang X, Parisi G, Saus CP, Torrejon DY, Graeber TG, CominAnduix B, Hu-Lieskovan S, Damoiseaux R, Lo RS, Ribas A. Interferon Receptor Signaling Pathways Regulating PD-L1 and PD-L2 Expression. Cell Reports. 2017. doi: 10.1016/j.celrep.2017.04.031. PubMed PMID: 28494868.

29. Ealick SE, Cook WJ, Vijay-Kumar S, Carson M, Nagabhushan TL, Trotta PP, Bugg CE. Three-dimensional structure of recombinant human interferon-gamma. Science. 1991;252(5006):698-702. Epub 1991/05/03. doi: 10.1126/science.1902591. PubMed PMID: 1902591. 
1020

1021

1022

1023

1024

1025

1026

1027

1028

1029

1030

1031

1032

1033

1034

1035

1036

1037

1038

1039

1040

1041

1042

1043

1044

1045

1046

1047

1048

1049

1050

1051

1052

1053

1054

1055

1056

1057

1058

1059

1060

1061

1062

1063

1064

1065
30. Pestka S, Krause CD, Walter MR. Interferons, interferon-like cytokines, and their receptors. Immunol Rev. 2004;202:8-32. Epub 2004/11/18. doi: 10.1111/j.01052896.2004.00204.x. PubMed PMID: 15546383.

31. Blouin CM, Lamaze C. Interferon gamma receptor: the beginning of the journey. Front Immunol. 2013;4:267. Epub 2013/09/13. doi: 10.3389/fimmu.2013.00267. PubMed PMID: 24027571; PMCID: PMC3760442.

32. Lasfar A, Cook JR, Cohen Solal KA, Reuhl K, Kotenko SV, Langer JA, Laskin DL. Critical role of the endogenous interferon ligand-receptors in type I and type II interferons response. Immunology. 2014;142(3):442-52. Epub 2014/03/07. doi: 10.1111/imm.12273. PubMed PMID: 24597649; PMCID: PMC4080960.

33. Meraz MA, White JM, Sheehan KC, Bach EA, Rodig SJ, Dighe AS, Kaplan DH, Riley JK, Greenlund AC, Campbell D, Carver-Moore K, DuBois RN, Clark R, Aguet M, Schreiber RD. Targeted disruption of the Stat 1 gene in mice reveals unexpected physiologic specificity in the JAK-STAT signaling pathway. Cell. 1996;84(3):431-42. Epub 1996/02/09. doi: 10.1016/s0092-8674(00)81288-x. PubMed PMID: 8608597.

34. Schroder K, Hertzog PJ, Ravasi T, Hume DA. Interferon-gamma: an overview of signals, mechanisms and functions. J Leukoc Biol. 2004;75(2):163-89. Epub 2003/10/04. doi: 10.1189/jlb.0603252. PubMed PMID: 14525967.

35. Lehtonen A, Matikainen S, Julkunen I. Interferons up-regulate STAT1, STAT2, and IRF family transcription factor gene expression in human peripheral blood mononuclear cells and macrophages. Journal of immunology (Baltimore, Md : 1950). 1997. PubMed PMID: 9218597.

36. Chen J, Feng Y, Lu L, Wang H, Dai L, Li Y, Zhang P. Interferon- $\gamma$-induced PD-L1 surface expression on human oral squamous carcinoma via PKD2 signal pathway. Immunobiology. 2012;217(4):385-93. Epub 2011/12/30. doi: 10.1016/j.imbio.2011.10.016. PubMed PMID: 22204817.

37. Walser TC, Ma X, Kundu N, Dorsey R, Goloubeva O, Fulton AM. Immune-mediated modulation of breast cancer growth and metastasis by the chemokine Mig (CXCL9) in a murine model. J Immunother. 2007;30(5):490-8. Epub 2007/06/26. doi: 10.1097/CJI.0b013e318031b551. PubMed PMID: 17589289.

38. Lyford-Pike S, Peng S, Young GD, Taube JM, Westra WH, Akpeng B, Bruno TC, Richmon JD, Wang H, Bishop JA, Chen L, Drake CG, Topalian SL, Pardoll DM, Pai SI. Evidence for a role of the PD-1:PD-L1 pathway in immune resistance of HPV-associated head and neck squamous cell carcinoma. Cancer Res. 2013;73(6):1733-41. Epub 2013/01/05. doi: 10.1158/0008-5472.Can-12-2384. PubMed PMID: 23288508; PMCID: PMC3602406.

39. Garrido F, Ruiz-Cabello F, Cabrera T, Pérez-Villar JJ, López-Botet M, Duggan-Keen M, Stern PL. Implications for immunosurveillance of altered HLA class I phenotypes in human tumours. Immunol Today. 1997;18(2):89-95. Epub 1997/02/01. doi: 10.1016/s01675699(96)10075-x. PubMed PMID: 9057360.

40. Beatty GL, Paterson Y. Regulation of tumor growth by IFN-gamma in cancer immunotherapy. Immunol Res. 2001;24(2):201-10. Epub 2001/10/12. doi: 10.1385/ir:24:2:201. PubMed PMID: 11594457.

41. Pollard KM, Cauvi DM, Toomey CB, Morris KV, Kono DH. Interferon- $\gamma$ and systemic autoimmunity. Discov Med. 2013;16(87):123-31. Epub 2013/09/04. PubMed PMID: 23998448; PMCID: PMC3934799. 
1066

1067

1068

1069

1070

1071

1072

1073

1074

1075

1076

1077

1078

1079

1080

1081

1082

1083

1084

1085

1086

1087

1088

1089

1090

1091

1092

1093

1094

1095

1096

1097

1098

1099

1100

1101

1102

1103

1104

1105

1106

1107

1108

1109

1110

1111
42. Lees JR, Cross AH. A little stress is good: IFN-gamma, demyelination, and multiple sclerosis. J Clin Invest. 2007;117(2):297-9. Epub 2007/02/03. doi: 10.1172/jci31254. PubMed PMID: 17273549; PMCID: PMC1783822.

43. Bustamante J, Boisson-Dupuis S, Abel L, Casanova J-L. Mendelian susceptibility to mycobacterial disease: genetic, immunological, and clinical features of inborn errors of IFN- $\gamma$ immunity. Seminars in Immunology. 2014;26(6):454 - 70.

44. Newport MJ, Huxley CM, Huston S, Hawrylowicz CM, Oostra BA, Williamson R, Levin M. A Mutation in the Interferon- $\gamma-$ Receptor Gene and Susceptibility to Mycobacterial Infection. New England Journal of Medicine. 1996;335(26):1941-9. doi: 10.1056/nejm199612263352602. PubMed PMID: 8960473.

45. Jouanguy E, Altare F, Lamhamedi S, Revy P, Emile J-F, Newport M, Levin M, Blanche S, Seboun E, Fischer A, Casanova J-L. Interferon- $\gamma$-Receptor Deficiency in an Infant with Fatal Bacille Calmette-Guérin Infection. New England Journal of Medicine. 1996;335(26):1956-62. doi: 10.1056/nejm199612263352604. PubMed PMID: 8960475.

46. Alcaïs A, Fieschi C, Abel L, Casanova J-L. Tuberculosis in children and adults: two distinct genetic diseases. The Journal of experimental medicine. 2005;202:1617-21. doi: 10.1084/jem.20052302. PubMed PMID: 16365144.

47. Bogunovic D, Byun M, Durfee LA, Abhyankar A, Sanal O, Mansouri D, Salem S, Radovanovic I, Grant AV, Adimi P, Mansouri N, Okada S, Bryant VL, Kong X-F, Kreins A, Velez MM, Boisson B, Khalilzadeh S, Ozcelik U, Darazam IA, Schoggins JW, Rice CM, Al-Muhsen S, Behr M, Vogt G, Puel A, Bustamante J, Gros P, Huibregtse JM, Abel L, Boisson-Dupuis S, Casanova J-L. Mycobacterial Disease and Impaired IFN- $\gamma$ Immunity in Humans with Inherited ISG15 Deficiency. Science. 2012;337.

48. Filipe-Santos O, Bustamante J, Chapgier A, Vogt G, de Beaucoudrey L, Feinberg J, Jouanguy E, Boisson-Dupuis S, Fieschi C, Picard C, Casanova J-L. Inborn errors of IL12/23- and IFN-gamma-mediated immunity: molecular, cellular, and clinical features. Seminars in immunology. 2006;18:347-61. doi: 10.1016/j.smim.2006.07.010. PubMed PMID: 16997570.

49. Kong XF, Vogt G, Itan Y, Macura-Biegun A, Szaflarska A, Kowalczyk D, Chapgier A, Abhyankar A, Furthner D, Djambas Khayat C, Okada S, Bryant VL, Bogunovic D, Kreins A, Moncada-Vélez M, Migaud M, Al-Ajaji S, Al-Muhsen S, Holland SM, Abel L, Picard C, Chaussabel D, Bustamante J, Casanova JL, Boisson-Dupuis S. Haploinsufficiency at the human IFNGR2 locus contributes to mycobacterial disease. Human Molecular Genetics. 2013. doi: $10.1093 / \mathrm{hmg} / \mathrm{dds} 484$.

50. Sharpe AH. Introduction to checkpoint inhibitors and cancer immunotherapy. Immunol Rev. 2017;276(1):5-8. Epub 2017/03/05. doi: 10.1111/imr.12531. PubMed PMID: 28258698; PMCID: PMC5362112.

51. Castro F, Cardoso AP, Goncalves RM, Serre K, Oliveira MJ. Interferon-Gamma at the Crossroads of Tumor Immune Surveillance or Evasion. Front Immunol. 2018;9:847. Epub 2018/05/22. doi: 10.3389/fimmu.2018.00847. PubMed PMID: 29780381; PMCID: PMC5945880.

52. George S, Miao D, Demetri GD, Adeegbe D, Rodig SJ, Shukla S, Lipschitz M, AminMansour A, Raut CP, Carter SL, Hammerman P, Freeman GJ, Wu CJ, Ott PA, Wong KK, Van Allen EM. Loss of PTEN Is Associated with Resistance to Anti-PD-1 Checkpoint Blockade Therapy in Metastatic Uterine Leiomyosarcoma. Immunity. 2017;46:197-204. doi: 10.1016/j.immuni.2017.02.001. PubMed PMID: 28228279. 
53. Gong B, Kiyotani K, Sakata S, Nagano S, Kumehara S, Baba S, Besse B, Yanagitani N, Friboulet L, Nishio M, Takeuchi K, Kawamoto H, Fujita N, Katayama R. Secreted PD-L1 variants mediate resistance to PD-L1 blockade therapy in non-small cell lung cancer. Journal of Experimental Medicine. 2019. doi: 10.1084/jem.20180870.

54. IFN $\gamma$ : signalling, epigenetics and roles in immunity, metabolism, disease and cancer immunotherapy, (2018).

55. Mahoney KM, Shukla SA, Patsoukis N, Chaudhri A, Browne EP, Arazi A, Eisenhaure TM, Pendergraft WF, Hua P, Pham HC, Bu X, Zhu B, Hacohen N, Fritsch EF, Boussiotis VA, Wu CJ, Freeman GJ. A secreted PD-L1 splice variant that covalently dimerizes and mediates immunosuppression. Cancer Immunology, Immunotherapy. 2019. doi: 10.1007/s00262-018-2282-1. PubMed PMID: 30564891.

56. Guak H, Al Habyan S, Ma EH, Aldossary H, Al-Masri M, Won SY, Ying T, Fixman ED, Jones RG, McCaffrey LM, Krawczyk CM. Glycolytic metabolism is essential for CCR7 oligomerization and dendritic cell migration. Nat Commun. 2018;9(1):2463. Epub 2018/06/27. doi: 10.1038/s41467-018-04804-6. PubMed PMID: 29941886; PMCID: PMC6018630.

57. Balic JJ, Albargy H, Luu K, Kirby FJ, Jayasekara WSN, Mansell F, Garama DJ, Nardo DD, Baschuk N, Louis C, Humphries F, Fitzgerald K, Latz E, Gough DJ, Mansell A. metabolic reprogramming and IL-1 $\beta$ expression. Nature Communications. 2020;11:1-11. doi: 10.1038/s41467-020-17669-5.

58. Carneiro FRG, Lepelley A, Seeley JJ, Hayden MS, Ghosh S. An Essential Role for ECSIT in Mitochondrial Complex I Assembly and Mitophagy in Macrophages. Cell Rep. 2018;22(10):2654-66. Epub 2018/03/08. doi: 10.1016/j.celrep.2018.02.051. PubMed PMID: 29514094; PMCID: PMC5909989.

59. Everts B, Amiel E, Huang SCC, Smith AM, Chang CH, Lam WY, Redmann V, Freitas TC, Blagih J, Van Der Windt GJW, Artyomov MN, Jones RG, Pearce EL, Pearce EJ. TLRdriven early glycolytic reprogramming via the kinases TBK1-IKK $\varepsilon$ supports the anabolic demands of dendritic cell activation. Nature Immunology. 2014;15:323-32. doi: 10.1038/ni.2833. PubMed PMID: 24562310.

60. Everts B, Amiel E, van der Windt GJ, Freitas TC, Chott R, Yarasheski KE, Pearce EL, Pearce EJ. Commitment to glycolysis sustains survival of NO-producing inflammatory dendritic cells. Blood. 2012;120(7):1422-31. Epub 2012/07/13. doi: 10.1182/blood-201203-419747. PubMed PMID: 22786879; PMCID: PMC3423780.

61. Jha AK, Huang SC, Sergushichev A, Lampropoulou V, Ivanova Y, Loginicheva E, Chmielewski K, Stewart KM, Ashall J, Everts B, Pearce EJ, Driggers EM, Artyomov MN. Network integration of parallel metabolic and transcriptional data reveals metabolic modules that regulate macrophage polarization. Immunity. 2015;42(3):419-30. Epub 2015/03/19. doi: 10.1016/j.immuni.2015.02.005. PubMed PMID: 25786174.

62. Liu PS, Wang H, Li X, Chao T, Teav T, Christen S, Di Conza G, Cheng WC, Chou CH, Vavakova M, Muret C, Debackere K, Mazzone M, Huang HD, Fendt SM, Ivanisevic J, Ho PC. alpha-ketoglutarate orchestrates macrophage activation through metabolic and epigenetic reprogramming. Nat Immunol. 2017;18(9):985-94. Epub 2017/07/18. doi: 10.1038/ni.3796. PubMed PMID: 28714978.

63. Mills EL, Kelly B, Logan A, Costa ASH, Varma M, Bryant CE, Tourlomousis P, Dabritz JHM, Gottlieb E, Latorre I, Corr SC, McManus G, Ryan D, Jacobs HT, Szibor M, Xavier RJ, Braun T, Frezza C, Murphy MP, O'Neill LA. Succinate Dehydrogenase Supports 
Metabolic Repurposing of Mitochondria to Drive Inflammatory Macrophages. Cell. 2016;167(2):457-70 e13. Epub 2016/09/27. doi: 10.1016/j.cell.2016.08.064. PubMed PMID: 27667687; PMCID: PMC5863951.

64. Jung SB, Choi MJ, Ryu D, Yi HS, Lee SE, Chang JY, Chung HK, Kim YK, Kang SG, Lee JH, Kim KS, Kim HJ, Kim CS, Lee CH, Williams RW, Kim H, Lee HK, Auwerx J, Shong M. Reduced oxidative capacity in macrophages results in systemic insulin resistance. Nat Commun. 2018;9(1):1551. Epub 2018/04/21. doi: 10.1038/s41467-018-03998-z. PubMed PMID: 29674655; PMCID: PMC5908799.

65. Palmieri EM, Gonzalez-Cotto M, Baseler WA, Davies LC, Ghesquiere B, Maio N, Rice CM, Rouault TA, Cassel T, Higashi RM, Lane AN, Fan TW, Wink DA, McVicar DW. Nitric oxide orchestrates metabolic rewiring in M1 macrophages by targeting aconitase 2 and pyruvate dehydrogenase. Nat Commun. 2020;11(1):698. Epub 2020/02/06. doi: 10.1038/s41467-020-14433-7. PubMed PMID: 32019928; PMCID: PMC7000728.

66. Wang F, Zhang S, Jeon R, Vuckovic I, Jiang X, Lerman A, Folmes CD, Dzeja PD, Herrmann J. Interferon Gamma Induces Reversible Metabolic Reprogramming of M1 Macrophages to Sustain Cell Viability and Pro-Inflammatory Activity. EBioMedicine. 2018. doi: 10.1016/j.ebiom.2018.02.009.

67. Baardman J, Verberk SGS, Prange KHM, van Weeghel M, van der Velden S, Ryan DG, Wust RCI, Neele AE, Speijer D, Denis SW, Witte ME, Houtkooper RH, O'Neill L A, Knatko EV, Dinkova-Kostova AT, Lutgens E, de Winther MPJ, Van den Bossche J. A Defective Pentose Phosphate Pathway Reduces Inflammatory Macrophage Responses during Hypercholesterolemia. Cell Rep. 2018;25(8):2044-52 e5. Epub 2018/11/22. doi: 10.1016/j.celrep.2018.10.092. PubMed PMID: 30463003.

68. Cheng SC, Quintin J, Cramer RA, Shepardson KM, Saeed S, Kumar V, GiamarellosBourboulis EJ, Martens JHA, Rao NA, Aghajanirefah A, Manjeri GR, Li Y, Ifrim DC, Arts RJW, Van Der Meer BMJW, Deen PMT, Logie C, O'Neill LA, Willems P, Van De Veerdonk FL, Van Der Meer JWM, Ng A, Joosten LAB, Wijmenga C, Stunnenberg HG, Xavier RJ, Netea MG. MTOR- and HIF-1 $\alpha$-mediated aerobic glycolysis as metabolic basis for trained immunity. Science. 2014. doi: 10.1126/science.1250684. PubMed PMID: 25258083.

69. Mills EL, Ryan DG, Prag HA, Dikovskaya D, Menon D, Zaslona Z, Jedrychowski MP, Costa ASH, Higgins M, Hams E, Szpyt J, Runtsch MC, King MS, McGouran JF, Fischer R, Kessler BM, McGettrick AF, Hughes MM, Carroll RG, Booty LM, Knatko EV, Meakin PJ, Ashford MLJ, Modis LK, Brunori G, Sévin DC, Fallon PG, Caldwell ST, Kunji ERS, Chouchani ET, Frezza C, Dinkova-Kostova AT, Hartley RC, Murphy MP, O'Neill LA. Itaconate is an anti-inflammatory metabolite that activates Nrf2 via alkylation of KEAP1. Nature. 2018. doi: 10.1038/nature25986. PubMed PMID: 29590092.

70. Tannahill GM, Curtis AM, Adamik J, Palsson-Mcdermott EM, McGettrick AF, Goel G, Frezza C, Bernard NJ, Kelly B, Foley NH, Zheng L, Gardet A, Tong Z, Jany SS, Corr SC, Haneklaus M, Caffrey BE, Pierce K, Walmsley S, Beasley FC, Cummins E, Nizet V, Whyte M, Taylor CT, Lin H, Masters SL, Gottlieb E, Kelly VP, Clish C, Auron PE, Xavier RJ, O'Neill LAJ. Succinate is an inflammatory signal that induces IL-1 $\beta$ through HIF-1 $\alpha$. Nature. 2013. doi: 10.1038/nature11986. PubMed PMID: 23535595.

71. Veldhoen M, Blankenhaus B, Konjar S, Ferreira C. Metabolic wiring of murine T cell and intraepithelial lymphocyte maintenance and activation. Eur J Immunol. 2018;48(9):143040. Epub 2018/07/26. doi: 10.1002/eji.201646745. PubMed PMID: 30043974. 
1204

1205

1206

1207

1208

1209

1210

1211

1212

1213

1214

1215

1216

1217

1218

1219

1220

1221

1222

1223

1224

1225

1226

1227

1228

1229

1230

1231

1232

1233

1234

1235

1236

1237

1238

1239

1240

1241

1242

1243

1244

1245

1246

1247

1248
72. Buck MD, O'Sullivan D, Pearce EL. T cell metabolism drives immunity. J Exp Med. 2015;212(9):1345-60. Epub 2015/08/12. doi: 10.1084/jem.20151159. PubMed PMID: 26261266 ; PMCID: PMC4548052.

73. Su X, Yu Y, Zhong Y, Giannopoulou EG, Hu X, Liu H, Cross JR, Rätsch G, Rice CM, Ivashkiv LB. Interferon- $\gamma$ regulates cellular metabolism and mRNA translation to potentiate macrophage activation. Nat Immunol. 2015;16(8):838-49. Epub 2015/07/07. doi: 10.1038/ni.3205. PubMed PMID: 26147685; PMCID: PMC4509841.

74. Doench JG, Fusi N, Sullender M, Hegde M, Vaimberg EW, Donovan KF, Smith I, Tothova Z, Wilen C, Orchard R, Virgin HW, Listgarten J, Root DE. Optimized sgRNA design to maximize activity and minimize off-target effects of CRISPR-Cas9. Nat Biotechnol. 2016;34(2):184-91. Epub 2016/01/19. doi: 10.1038/nbt.3437. PubMed PMID: 26780180; PMCID: PMC4744125.

75. Li W, Koster J, Xu H, Chen CH, Xiao T, Liu JS, Brown M, Liu XS. Quality control, modeling, and visualization of CRISPR screens with MAGeCK-VISPR. Genome Biol. 2015;16:281. Epub 2015/12/18. doi: 10.1186/s13059-015-0843-6. PubMed PMID: 26673418; PMCID: PMC4699372.

76. Ferwerda G, Girardin SE, Kullberg BJ, Le Bourhis L, De Jong DJ, Langenberg DML, Van Crevel R, Adema GJ, Ottenhoff THM, Van Der Meer JWM, Netea MG. NOD2 and tolllike receptors are nonredundant recognition systems of Mycobacterium tuberculosis. PLoS Pathogens. 2005. doi: 10.1371/journal.ppat.0010034.

77. Chapoval AI, Ni J, Lau JS, Wilcox RA, Flies DB, Liu D, Dong H, Sica GL, Zhu G, Tamada K, Chen L. B7-H3: A costimulatory molecule for T cell activation and IFN- $\gamma$ production. Nature Immunology. 2001. doi: 10.1038/85339. PubMed PMID: 11224528.

78. Steimle V, Durand B, Barras E, Zufferey M, Hadam MR, Mach B, Reith W. A novel DNAbinding regulatory factor is mutated in primary MHC class II deficiency (bare lymphocyte syndrome). Genes and Development. 1995. doi: 10.1101/gad.9.9.1021. PubMed PMID: 7744245.

79. Kiritsy MC, Ankley LM, Trombley JD, Huizinga GP, Lord AE, Orning P, Elling R, Fitzgerald KA, Olive AJ. A genome-wide screen in macrophages identifies new regulators of IFN $\gamma$-inducible MHCII that contribute to T cell activation. bioRxiv. 2020.

80. Gu W, Chen J, Yang L, Zhao KN. TNF-alpha promotes IFN-gamma-induced CD40 expression and antigen process in Myb-transformed hematological cells.

ScientificWorldJournal. 2012;2012:621969. Epub 2012/05/02. doi: 10.1100/2012/621969. PubMed PMID: 22547990; PMCID: PMC3322478.

81. Kataoka K, Shiraishi Y, Takeda Y, Sakata S, Matsumoto M, Nagano S, Maeda T, Nagata Y, Kitanaka A, Mizuno S, Tanaka H, Chiba K, Ito S, Watatani Y, Kakiuchi N, Suzuki H, Yoshizato T, Yoshida K, Sanada M, Itonaga H, Imaizumi Y, Totoki Y, Munakata W, Nakamura H, Hama N, Shide K, Kubuki Y, Hidaka T, Kameda T, Masuda K, Minato N, Kashiwase K, Izutsu K, Takaori-Kondo A, Miyazaki Y, Takahashi S, Shibata T, Kawamoto H, Akatsuka Y, Shimoda K, Takeuchi K, Seya T, Miyano S, Ogawa S. Aberrant PD-L1 expression through 3'-UTR disruption in multiple cancers. Nature. 2016;534:402-6. doi: 10.1038/nature18294. PubMed PMID: 27281199.

82. Burr ML, Sparbier CE, Chan YC, Williamson JC, Woods K, Beavis PA, Lam EYN, Henderson MA, Bell CC, Stolzenburg S, Gilan O, Bloor S, Noori T, Morgens DW, Bassik MC, Neeson PJ, Behren A, Darcy PK, Dawson SJ, Voskoboinik I, Trapani JA, Cebon J, 
Lehner PJ, Dawson MA. CMTM6 maintains the expression of PD-L1 and regulates antiTumour immunity. Nature. 2017. doi: 10.1038/nature23643. PubMed PMID: 28813417.

83. Coelho MA, de Carné Trécesson S, Rana S, Zecchin D, Moore C, Molina-Arcas M, East P, Spencer-Dene B, Nye E, Barnouin K, Snijders AP, Lai WS, Blackshear PJ, Downward J. Oncogenic RAS Signaling Promotes Tumor Immunoresistance by Stabilizing PD-L1 mRNA. Immunity. 2017;47:1083-99.e6. doi: 10.1016/j.immuni.2017.11.016.

84. Manguso RT, Pope HW, Zimmer MD, Brown FD, Yates KB, Miller BC, Collins NB, Bi K, LaFleur MW, Juneja VR, Weiss SA, Lo J, Fisher DE, Miao D, Van Allen E, Root DE, Sharpe AH, Doench JG, Haining WN. In vivo CRISPR screening identifies Ptpn2 as a cancer immunotherapy target. Nature. 2017;547(7664):413-8. Epub 2017/07/21. doi: 10.1038/nature23270. PubMed PMID: 28723893; PMCID: PMC5924693.

85. Mezzadra R, Sun C, Jae LT, Gomez-Eerland R, De Vries E, Wu W, Logtenberg MEW, Slagter M, Rozeman EA, Hofland I, Broeks A, Horlings HM, Wessels LFA, Blank CU, Xiao Y, Heck AJR, Borst J, Brummelkamp TR, Schumacher TNM. Identification of CMTM6 and CMTM4 as PD-L1 protein regulators. Nature. 2017. doi: 10.1038/nature23669. PubMed PMID: 28813410.

86. Hassounah NB, Malladi VS, Huang Y, Freeman SS, Beauchamp EM, Koyama S, Souders N, Martin S, Dranoff G, Wong KK, Pedamallu CS, Hammerman PS, Akbay EA. Identification and characterization of an alternative cancer-derived PD-L1 splice variant. Cancer Immunology, Immunotherapy. 2019. doi: 10.1007/s00262-018-2284-z. PubMed PMID: 30564890.

87. Kriegsman BA, Vangala P, Chen BJ, Meraner P, Brass AL, Garber M, Rock KL. Frequent Loss of IRF2 in Cancers Leads to Immune Evasion through Decreased MHC Class I Antigen Presentation and Increased PD-L1 Expression. The Journal of Immunology. 2019;203:1999-2010. doi: 10.4049/jimmunol.1900475. PubMed PMID: 31471524.

88. Papalexi E, Mimitou E, Butler AW, Foster S, Bracken B, Mauck WM, Wessels H-H, Yeung BZ, Smibert P, Satija R. Characterizing the molecular regulation of inhibitory immune checkpoints with multi-modal single-cell screens. bioRxiv.

2020:2020.06.28.175596. doi: 10.1101/2020.06.28.175596.

89. Wang P, Geng J, Gao J, Zhao H, Li J, Shi Y, Yang B, Xiao C, Linghu Y, Sun X, Chen X, Hong L, Qin F, Li X, Yu JS, You H, Yuan Z, Zhou D, Johnson RL, Chen L. Macrophage achieves self-protection against oxidative stress-induced ageing through the Mst-Nrf2 axis. Nat Commun. 2019;10(1):755. Epub 2019/02/16. doi: 10.1038/s41467-019-08680-6. PubMed PMID: 30765703; PMCID: PMC6376064.

90. Wijdeven RH, van Luijn MM, Wierenga-Wolf AF, Akkermans JJ, van den Elsen PJ, Hintzen RQ, Neefjes J. Chemical and genetic control of IFNgamma-induced MHCII expression. EMBO Rep. 2018;19(9). Epub 2018/07/20. doi: 10.15252/embr.201745553. PubMed PMID: 30021835; PMCID: PMC6123650.

91. Liu B, Liao J, Rao X, Kushner SA, Chung CD, Chang DD, Shuai K. Inhibition of Stat1mediated gene activation by PIAS1. Proc Natl Acad Sci U S A. 1998;95(18):10626-31. Epub 1998/09/02. doi: 10.1073/pnas.95.18.10626. PubMed PMID: 9724754; PMCID: PMC27945.

92. Subramanian A, Tamayo P, Mootha VK, Mukherjee S, Ebert BL, Gillette MA, Paulovich A, Pomeroy SL, Golub TR, Lander ES, Mesirov JP. Gene set enrichment analysis: A knowledge-based approach for interpreting genome-wide expression profiles. Proceedings 
of the National Academy of Sciences of the United States of America. 2005. doi: 10.1073/pnas.0506580102. PubMed PMID: 16199517.

93. Stroud DA, Surgenor EE, Formosa LE, Reljic B, Frazier AE, Dibley MG, Osellame LD, Stait T, Beilharz TH, Thorburn DR, Salim A, Ryan MT. Accessory subunits are integral for assembly and function of human mitochondrial complex I. Nature. 2016;538(7623):123-6. Epub 2016/09/15. doi: 10.1038/nature19754. PubMed PMID: 27626371.

94. Lazarou M, McKenzie M, Ohtake A, Thorburn DR, Ryan MT. Analysis of the Assembly Profiles for Mitochondrial- and Nuclear-DNA-Encoded Subunits into Complex I. Molecular and Cellular Biology. 2007;27:4228-37.

95. Pagliarini DJ, Calvo SE, Chang B, Sheth SA, Vafai SB, Ong SE, Walford GA, Sugiana C, Boneh A, Chen WK, Hill DE, Vidal M, Evans JG, Thorburn DR, Carr SA, Mootha VK. A mitochondrial protein compendium elucidates complex I disease biology. Cell. 2008;134(1):112-23. Epub 2008/07/11. doi: 10.1016/j.cell.2008.06.016. PubMed PMID: 18614015 ; PMCID: PMC2778844.

96. Baradaran R, Berrisford JM, Minhas GS, Sazanov LA. Crystal structure of the entire respiratory complex I. Nature. 2013;494(7438):443-8. doi: 10.1038/nature11871.

97. Zickermann V, Wirth C, Nasiri H, Siegmund K, Schwalbe H, Hunte C, Brandt U. Mechanistic insight from the crystal structure of mitochondrial complex I. Science. 2015;347:44-9.

98. Zhu J, Vinothkumar KR, Hirst J. Structure of mammalian respiratory complex I. Nature. 2016;536(7616):354-8. doi: 10.1038/nature19095.

99. Barrientos A, Moraes CT. Titrating the effects of mitochondrial complex I impairment in the cell physiology. J Biol Chem. 1999;274(23):16188-97. Epub 1999/05/29. doi: 10.1074/jbc.274.23.16188. PubMed PMID: 10347173.

100. Brand MD, Nicholls DG. Assessing mitochondrial dysfunction in cells. Biochem J. 2011;435(2):297-312. Epub 2011/07/06. doi: 10.1042/BJ20110162. PubMed PMID: $21726199 ;$ PMCID: PMC3076726.

101. Vacanti Nathaniel M, Divakaruni Ajit S, Green Courtney R, Parker Seth J, Henry Robert R, Ciaraldi Theodore P, Murphy Anne N, Metallo Christian M. Regulation of Substrate Utilization by the Mitochondrial Pyruvate Carrier. Molecular Cell. 2014;56(3):425-35. doi: https://doi.org/10.1016/j.molcel.2014.09.024.

102. De Vriese AS, Van Coster R, Smet J, Seneca S, Lovering A, Van Haute LL, Vanopdenbosch LJ, Martin JJ, Ceuterick-De Groote C, Vandecasteele S, Boelaert JR. Linezolid-induced inhibition of mitochondrial protein synthesis. Clinical Infectious Diseases. 2006;42:1111-7. doi: 10.1086/501356.

103. Soriano A, Miró O, Mensa J. Mitochondrial Toxicity Associated with Linezolid. New England Journal of Medicine. 2005;353:2305-6. doi: 10.1056/NEJM200511243532123.

104. Wilson DN, Schluenzen F, Harms JM, Starosta AL, Connell SR, Fucini P. The oxazolidinone antibiotics perturb the ribosomal peptidyl-transferase center and effect tRNA positioning. Proc Natl Acad Sci U S A. 2008;105(36):13339-44. Epub 2008/09/02. doi: 10.1073/pnas.0804276105. PubMed PMID: 18757750; PMCID: PMC2533191.

105. Bustamante E, Morris HP, Pedersen PL. Hexokinase: The Direct Link between Mitochondrial and Glycolytic Reactions in Rapidly Growing Cancer Cells. Springer, Boston, MA; 1978. p. 363-80.

106. Cramer T, Yamanishi Y, Clausen BE, Förster I, Pawlinski R, Mackman N, Haase VH, Jaenisch R, Corr M, Nizet V, Firestein GS, Gerber HP, Ferrara N, Johnson RS. HIF-1 $\alpha$ is 
essential for myeloid cell-mediated inflammation. Cell. 2003;112:645-57. doi: 10.1016/S0092-8674(03)00154-5. PubMed PMID: 12628185.

107. Hypoxia-inducible factors in physiology and medicine, (2012).

108. Braverman J, Stanley SA. Nitric Oxide Modulates Macrophage Responses to Mycobacterium tuberculosis Infection through Activation of HIF-1 $\alpha$ and Repression of NF$\kappa \mathrm{B}$ The Journal of Immunology. 2017. doi: 10.4049/jimmunol.1700515.

109. Mishra BB, Rathinam VAK, Martens GW, Martinot AJ, Kornfeld H, Fitzgerald KA, Sassetti CM. Nitric oxide controls the immunopathology of tuberculosis by inhibiting NLRP3 inflammasome-dependent processing of IL-1 $\beta$. Nature Immunology. 2013. doi: 10.1038/ni.2474.

110. Wang GG, Calvo KR, Pasillas MP, Sykes DB, Häcker H, Kamps MP. Quantitative production of macrophages or neutrophils ex vivo using conditional Hoxb8. Nature Methods. 2006. doi: 10.1038/nmeth865.

111. Redecke V, Wu R, Zhou J, Finkelstein D, Chaturvedi V, High AA, Häcker H. Hematopoietic progenitor cell lines with myeloid and lymphoid potential. Nature Methods. 2013. doi: 10.1038/nmeth.2510.

112. Gallegos AM, Pamer EG, Glickman MS. Delayed protection by ESAT-6-specific effector CD4+ T cells after airborne M. tuberculosis infection. Journal of Experimental Medicine. 2008. doi: 10.1084/jem.20080353. PubMed PMID: 18779346.

113. Bhat MY, Solanki HS, Advani J, Khan AA, Keshava Prasad TS, Gowda H, Thiyagarajan S, Chatterjee A. Comprehensive network map of interferon gamma signaling. J Cell Commun Signal. 2018;12(4):745-51. Epub 2018/09/08. doi: 10.1007/s12079-018-0486-y. PubMed PMID: 30191398; PMCID: PMC6235777.

114. Cameron AM, Castoldi A, Sanin DE, Flachsmann LJ, Field CS, Puleston DJ, Kyle RL, Patterson AE, Hässler F, Buescher JM, Kelly B, Pearce EL, Pearce EJ. Inflammatory macrophage dependence on NAD + salvage is a consequence of reactive oxygen speciesmediated DNA damage. Nature Immunology. 2019. doi: 10.1038/s41590-019-0336-y.

115. Venter G, Oerlemans FTJJ, Willemse M, Wijers M, Fransen JAM, Wieringa B. NAMPTMediated Salvage Synthesis of NAD+ Controls Morphofunctional Changes of Macrophages. PLoS ONE. 2014;9:e97378. doi: 10.1371/journal.pone.0097378.

116. Minhas PS, Liu L, Moon PK, Joshi AU, Dove C, Mhatre S, Contrepois K, Wang Q, Lee BA, Coronado M, Bernstein D, Snyder MP, Migaud M, Majeti R, Mochly-Rosen D, Rabinowitz JD, Andreasson KI. Macrophage de novo NAD $(+)$ synthesis specifies immune function in aging and inflammation. Nat Immunol. 2019;20(1):50-63. Epub 2018/11/28. doi: 10.1038/s41590-018-0255-3. PubMed PMID: 30478397; PMCID: PMC6768398.

117. Lv H, Lv G, Chen C, Zong Q, Jiang G, Ye D, Cui X, He Y, Xiang W, Han Q, Tang L, Yang W, Wang H. NAD(+) Metabolism Maintains Inducible PD-L1 Expression to Drive Tumor Immune Evasion. Cell Metab. 2020. Epub 2020/11/11. doi: 10.1016/j.cmet.2020.10.021. PubMed PMID: 33171124.

118. Heng TS, Painter MW. The Immunological Genome Project: networks of gene expression in immune cells. Nat Immunol. 2008;9(10):1091-4. Epub 2008/09/19. doi: 10.1038/ni10081091. PubMed PMID: 18800157.

119. Lipid and small-molecule display by CD1 and MR1, (2015).

120. Benson SA, Ernst JD. TLR2-dependent inhibition of macrophage responses to IFN- $\gamma$ is mediated by distinct, gene-specific mechanisms. PLoS ONE. 2009. doi: 10.1371/journal.pone.0006329. PubMed PMID: 19629181. 
1386

1387

1388

1389

1390

1391

1392

1393

1394

1395

1396

1397

1398

1399

1400

1401

1402

1403

1404

1405

1406

1407

1408

1409

1410

1411

1412

1413

1414

1415

1416

1417

1418

1419

1420

1421

1422

1423

1424

1425

1426

1427

1428

1429

1430

121. Fortune SM, Solache A, Jaeger A, Hill PJ, Belisle JT, Bloom BR, Rubin EJ, Ernst JD. Mycobacterium tuberculosis Inhibits Macrophage Responses to IFN- $\gamma$ through Myeloid Differentiation Factor 88-Dependent and -Independent Mechanisms The Journal of Immunology. 2004. doi: 10.4049/jimmunol.172.10.6272. PubMed PMID: 15128816.

122. Kincaid EZ, Wolf AJ, Desvignes L, Mahapatra S, Crick DC, Brennan PJ, Pavelka MS, Jr., Ernst JD. Codominance of TLR2-dependent and TLR2-independent modulation of MHC class II in Mycobacterium tuberculosis infection in vivo. J Immunol. 2007;179(5):3187-95. Epub 2007/08/22. doi: 10.4049/jimmunol.179.5.3187. PubMed PMID: 17709534.

123. Su YM, Teemu P.; Mu, Luye; Mirek, Emily; Manalis, Scott R.; Anthony, Tracy G.; Sesaki, Hiromi; Chen, Jianzhu. Disassembly of ETC Complexes Drives Macrophage Inflammatory Responses by Reprogramming Cellular Metabolism and Translation. Available at SSRN: https://ssrncom/abstract=3611881 or http://dxdoiorg/102139/ssrn3611881. 2020.

124. Jang S, Javadov S. OPA1 regulates respiratory supercomplexes assembly: The role of mitochondrial swelling. Mitochondrion. 2020. doi: 10.1016/j.mito.2019.11.006. PubMed PMID: 31870826.

125. Blasi E, Radzioch D, Merletti L, Varesio L. Generation of macrophage cell line from fresh bone marrow cells with a myc/raf recombinant retrovirus. Cancer biochemistry biophysics. 1989. PubMed PMID: 2695237.

126. Joung J, Konermann S, Gootenberg JS, Abudayyeh OO, Platt RJ, Brigham MD, Sanjana NE, Zhang F. Genome-scale CRISPR-Cas9 knockout and transcriptional activation screening. Nature Protocols. 2017. doi: 10.1038/nprot.2017.016. PubMed PMID: 28333914.

127. Brown MB. 400: A Method for Combining Non-Independent, One-Sided Tests of Significance. Biometrics. 1975;31(4):987-92. doi: 10.2307/2529826.

128. Jia G, Wang X, Xiao G. A permutation-based non-parametric analysis of CRISPR screen data. BMC Genomics. 2017;18(1):545. Epub 2017/07/21. doi: 10.1186/s12864-017-39385. PubMed PMID: 28724352; PMCID: PMC5518132.

129. Bodapati S, Daley TP, Lin X, Zou J, Qi LS. A benchmark of algorithms for the analysis of pooled CRISPR screens. Genome Biology. 2020;21(1):62. doi: 10.1186/s13059-02001972-x.

130. Merico D, Isserlin R, Stueker O, Emili A, Bader GD. Enrichment map: A network-based method for gene-set enrichment visualization and interpretation. PLoS ONE. 2010. doi: 10.1371/journal.pone.0013984. PubMed PMID: 21085593.

131. Reimand J, Isserlin R, Voisin V, Kucera M, Tannus-Lopes C, Rostamianfar A, Wadi L, Meyer M, Wong J, Xu C, Merico D, Bader GD. Pathway enrichment analysis and visualization of omics data using g:Profiler, GSEA, Cytoscape and EnrichmentMap. Nature Protocols. 2019. doi: 10.1038/s41596-018-0103-9. PubMed PMID: 30664679.

132. Fulco CP, Munschauer M, Anyoha R, Munson G, Grossman SR, Perez EM, Kane M, Cleary B, Lander ES, Engreitz JM. Systematic mapping of functional enhancer-promoter connections with CRISPR interference. Science. 2016. doi: 10.1126/science.aag2445.

133. Field CS, Baixauli F, Kyle RL, Puleston DJ, Cameron AM, Sanin DE, Hippen KL, Loschi M, Thangavelu G, Corrado M, Edwards-Hicks J, Grzes KM, Pearce EJ, Blazar BR, Pearce EL. Mitochondrial Integrity Regulated by Lipid Metabolism Is a Cell-Intrinsic Checkpoint for Treg Suppressive Function. Cell Metabolism. 2020. doi: 10.1016/j.cmet.2019.11.021. PubMed PMID: 31883840. 
bioRxiv preprint doi: https://doi.org/10.1101/202011.22 393538; this version posted November 23, 2020. The copyright holder for this preprint

(which was not certified by peer review) is the author/funder, who has granted bioRxiv a license to display the preprint in perpetuity. It is made available under aCC-BY-ND 4.0 International license.

1431 134. Horlbeck MA, Xu A, Wang M, Bennett NK, Park CY, Bogdanoff D, Adamson B, Chow ED, Kampmann M, Peterson TR, Nakamura K, Fischbach MA, Weissman JS, Gilbert LA. Mapping the Genetic Landscape of Human Cells. Cell. 2018. doi:

1433 10.1016/j.cell.2018.06.010. PubMed PMID: 30033366.

1434

1435 
bioRxiv preprint doi: https://doi.org/10.1101/2020.11.22.393538; this version posted November 23, 2020. The copyright holder for this preprint (which was not certified by peer review) is the author/funder, who has granted bioRxiv a license to display the preprint in perpetuity. It is made

A

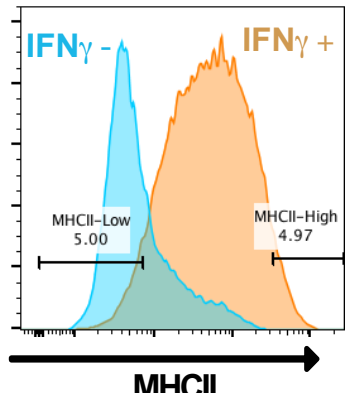

MHCll
B

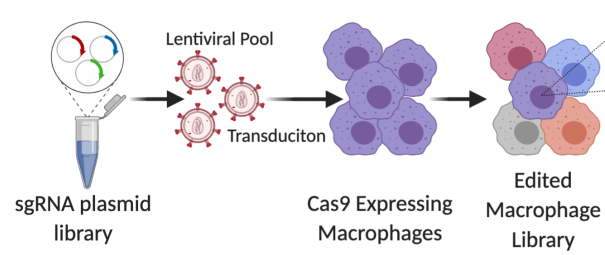

C

$H 2-A b 1$

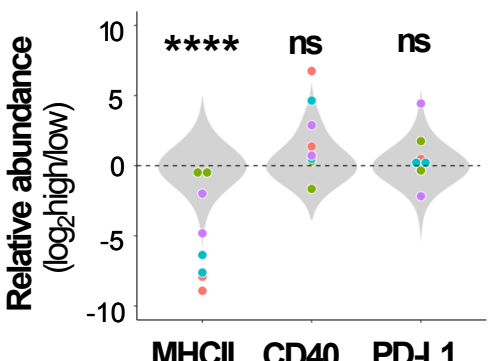

$E$

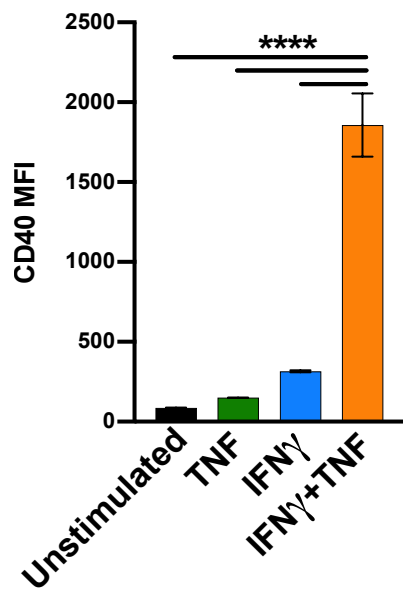

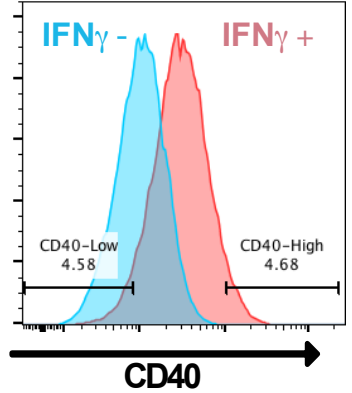

available Fifgêfre $\mathbf{1} \mathbf{1}$

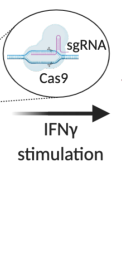

Cd40

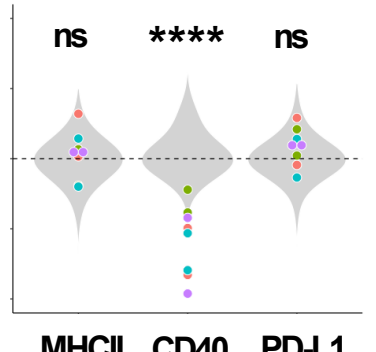

MHCII CD40 PD-L1

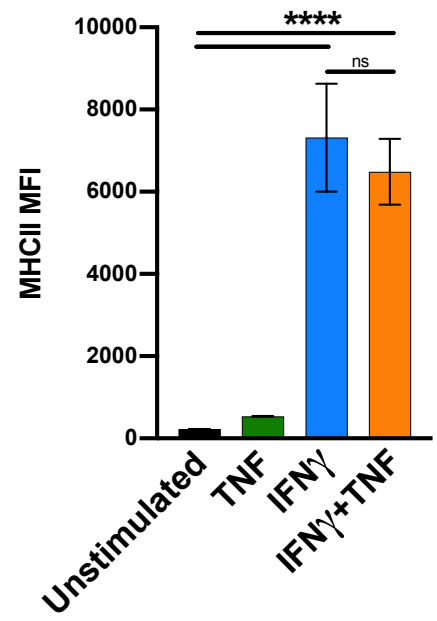

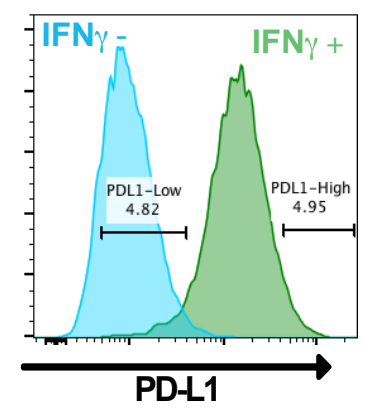

D

1

2

3

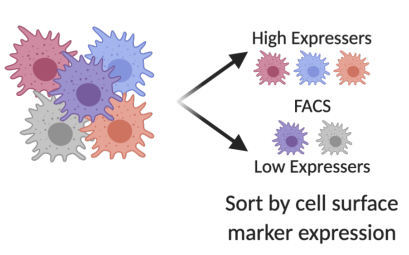

Cd274 (PD-L1)

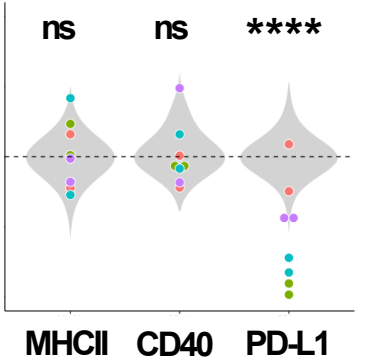

MHCII CD40 PD-L1

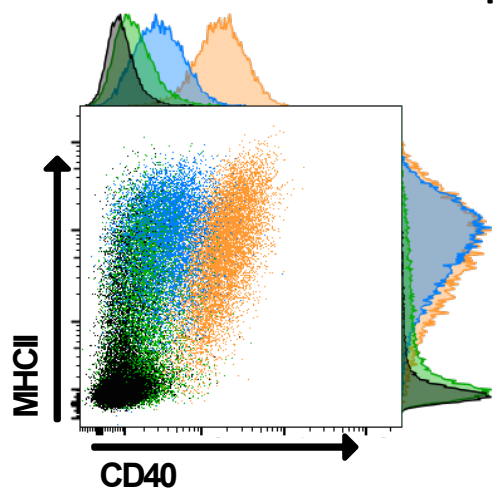

6

7

8

5
2

1

0

$-1$
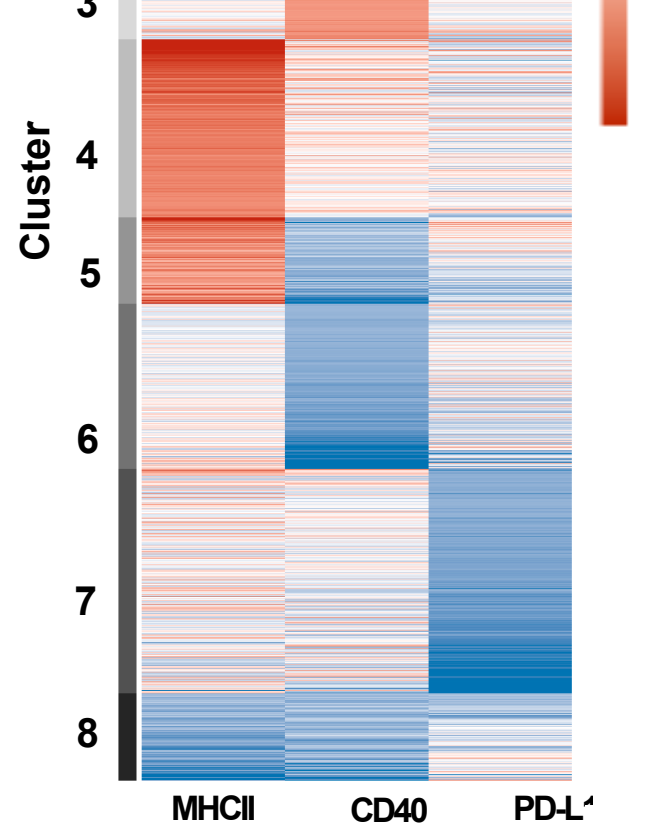

F

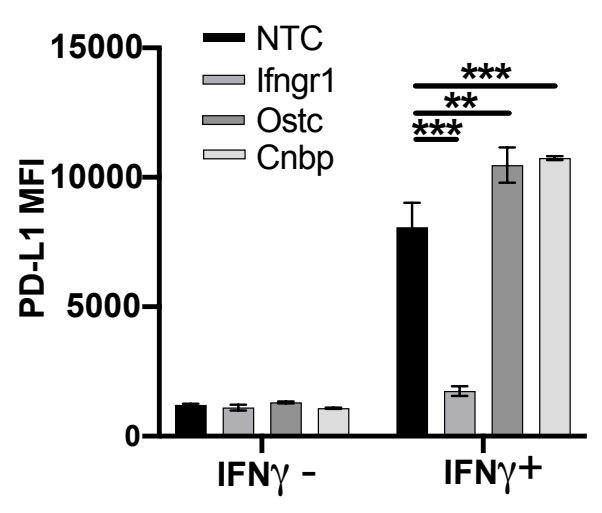


bioRxiv preprint doi: https://doi.org/10.1101/2020.11.22.393538; this version posted November 23,2020 . The copyright holder for this preprint (which was not certified by peer review) is the author/funder, who has granted bioRxiv a license to display the preprint in perpetuity. It is made available under aCC-BY-ND 4.0 International license.

Figure 2

A

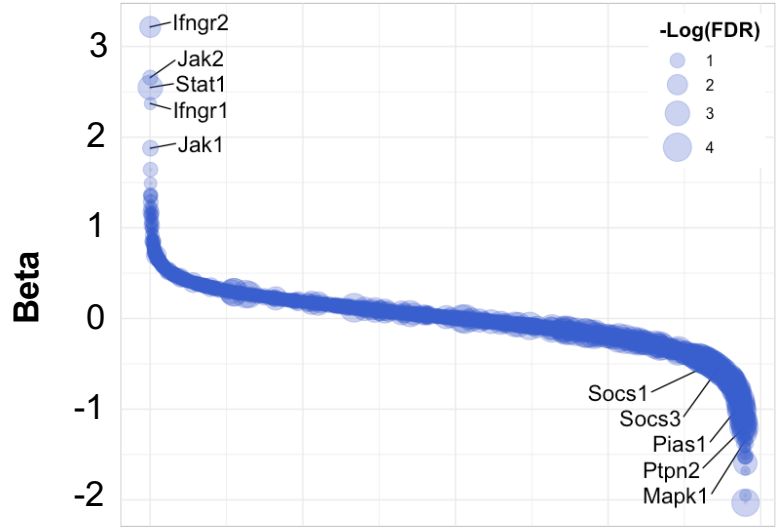

Rank
B

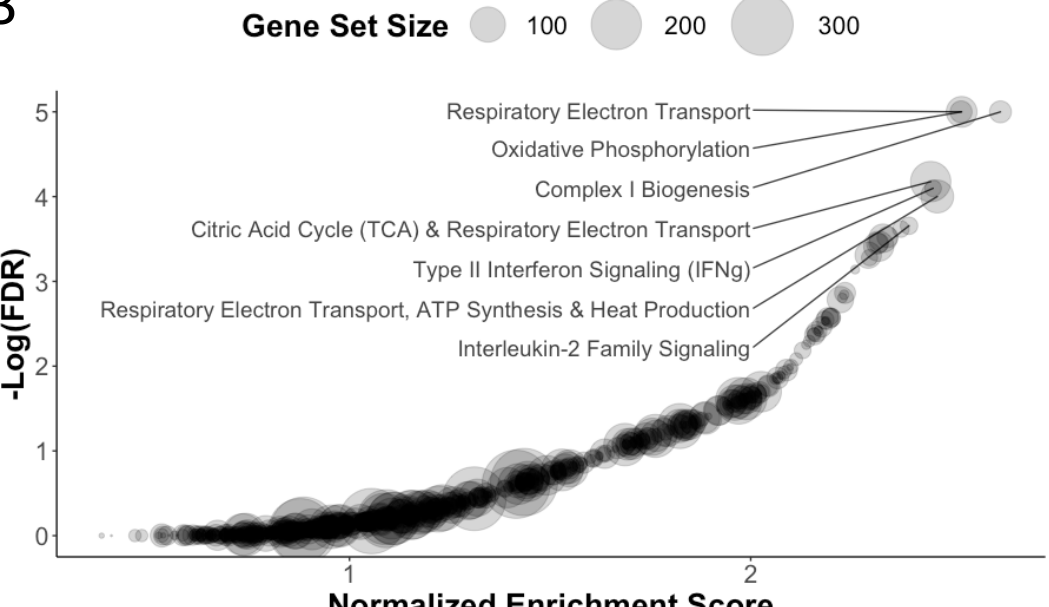

C

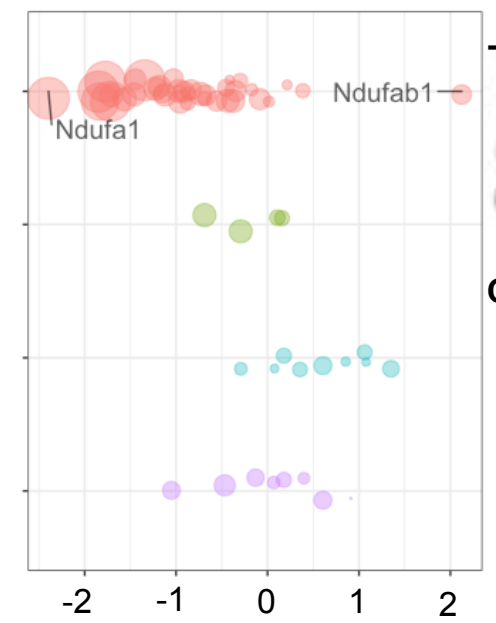

Relative Enrichment (Log2 FC)
- $\log ($ FDR)

.5
1
1.5
2
ETC
Complex
Cl
CII
CIII
CIV

$E$

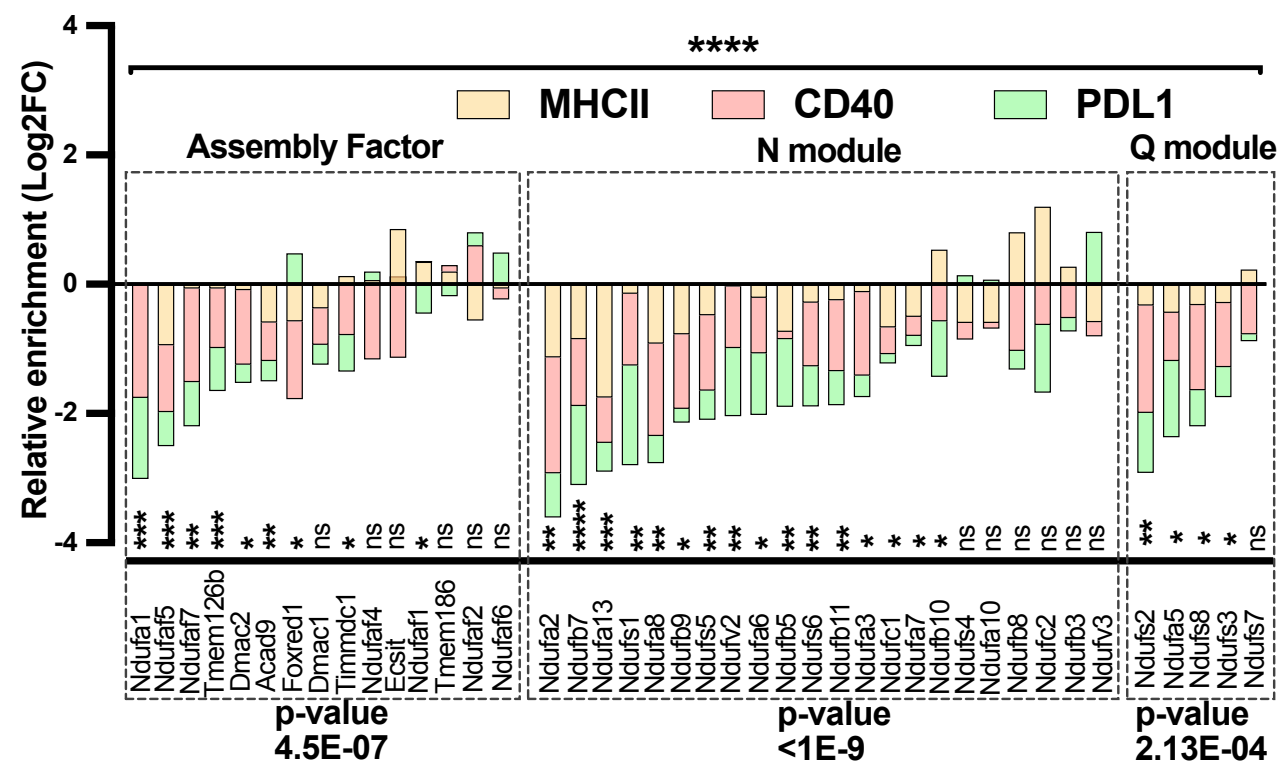

Complex I Subunit [Module]

\section{$\mathrm{N}$-module abundance (relative protein)}

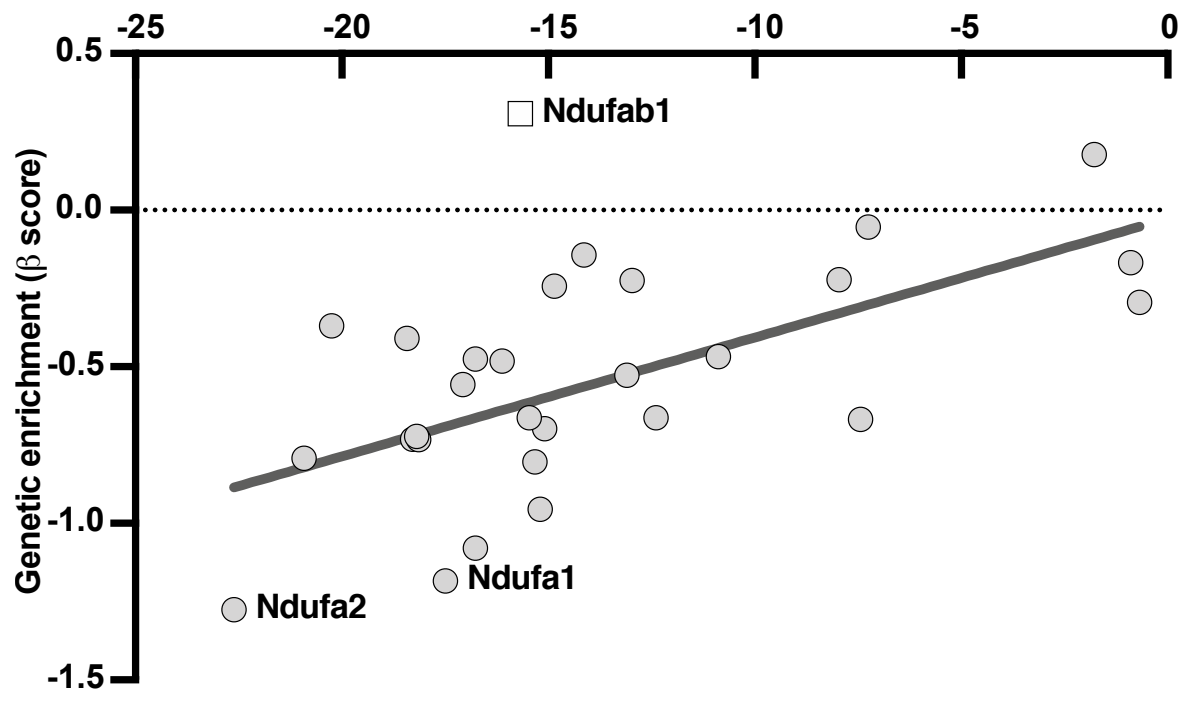


bioRxiv preprint doi: https://doi.org/10.1101/2020.11.22.393538; this version posted November 23, 2020. The copyright holder for this preprint

(which was not certified by peer review) is the author/funder, who has granted bioRxiv a license to display the preprint in perpetuity. It is made

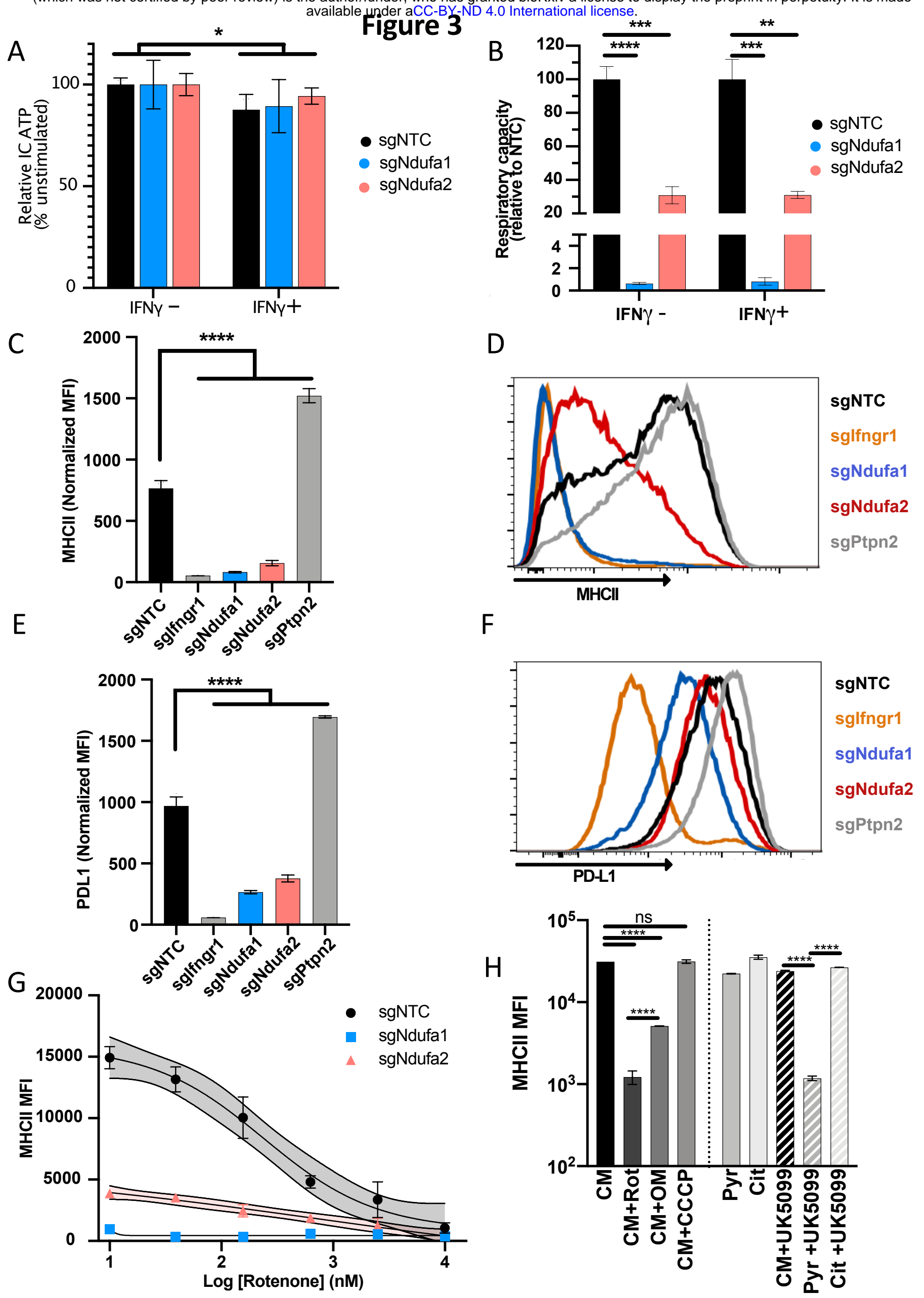


A

Figure 4
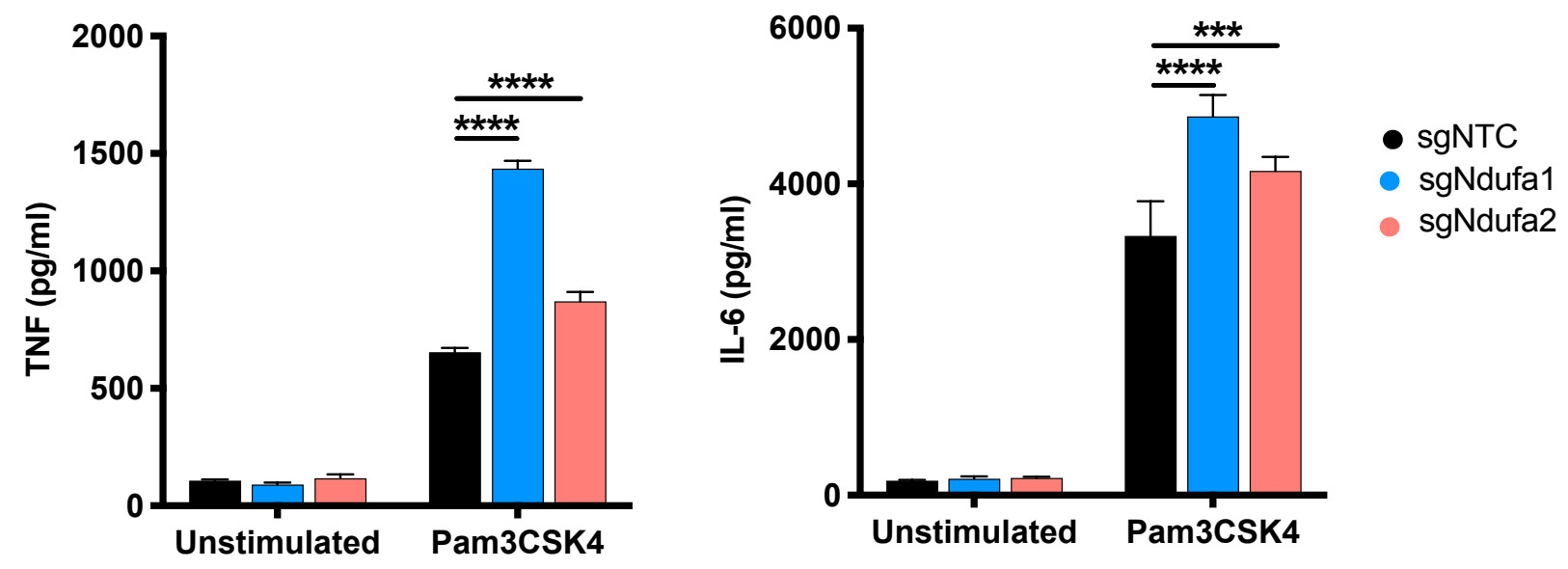

B

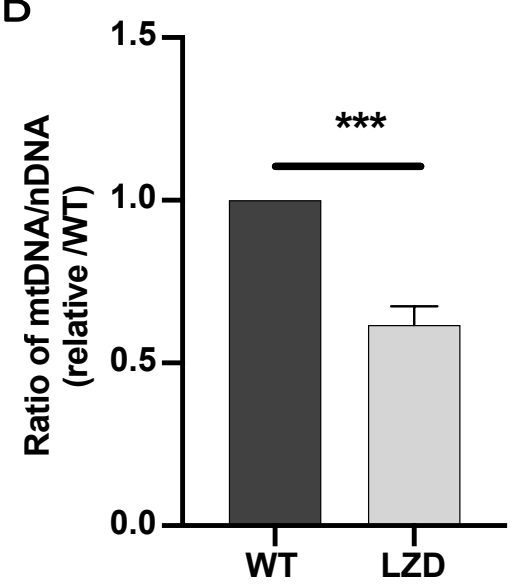

D

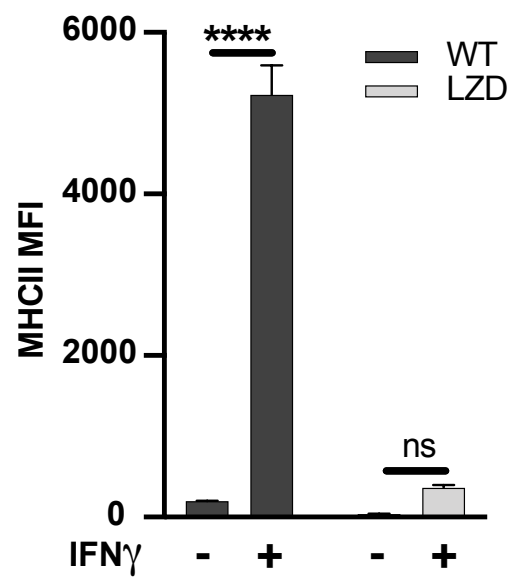

C

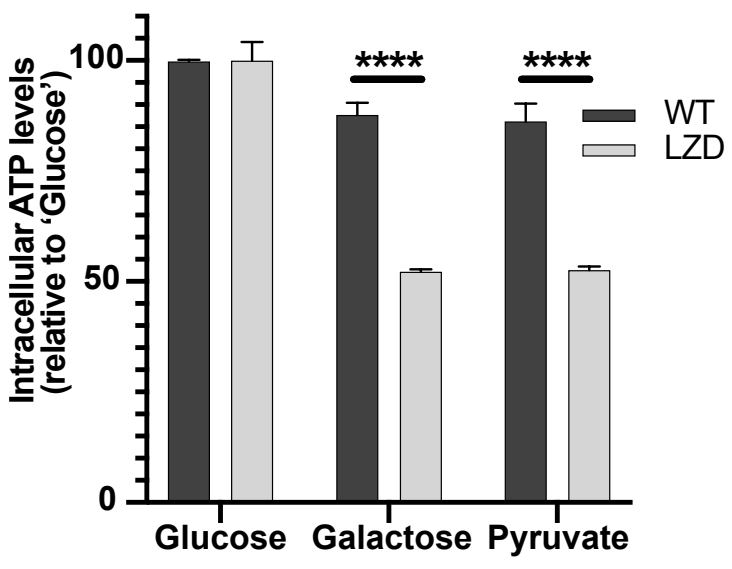

$\mathrm{E}$

F

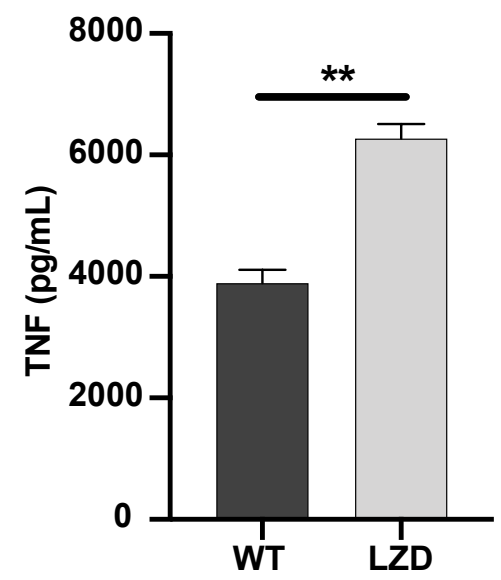

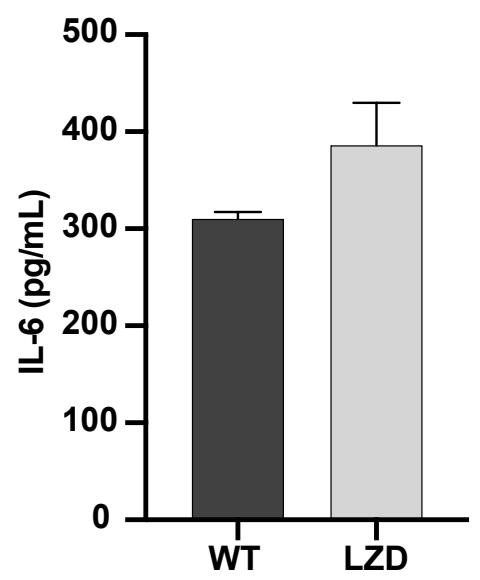


bioRxiv preprint doi: https://doi.org/10.1101/2020.11.22 393538; this version posted November 23, 2020. The copyright holder for this preprint (which was not certified by peer review) is the author/funder, who has granted bioRxiv a license to display the preprint in perpetuity. It is made available under aCC-BY-ND 4.0 International license.

Figure 5

A
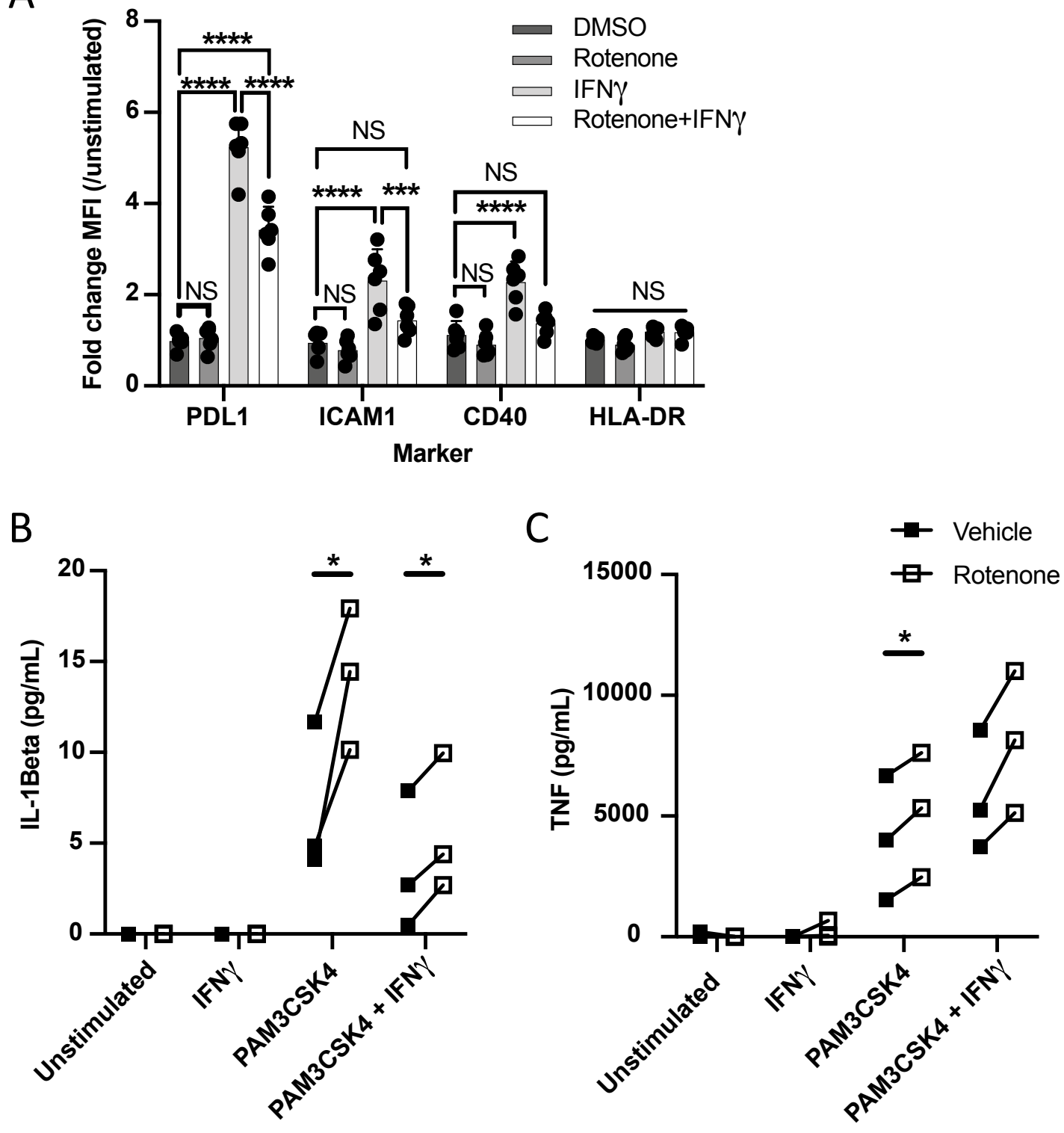
bioRxiv preprint doi: https://doi.org/10.1101/2020.11.22.393538; this version posted November 23, 2020. The copyright holder for this preprint

(which was not certified by peer review) is the author/funder, who has granted bioRxiv a license to display the preprint in perpetuity. It is made available under aCC-BY-ND 4.0 International license.

Figure 6

A
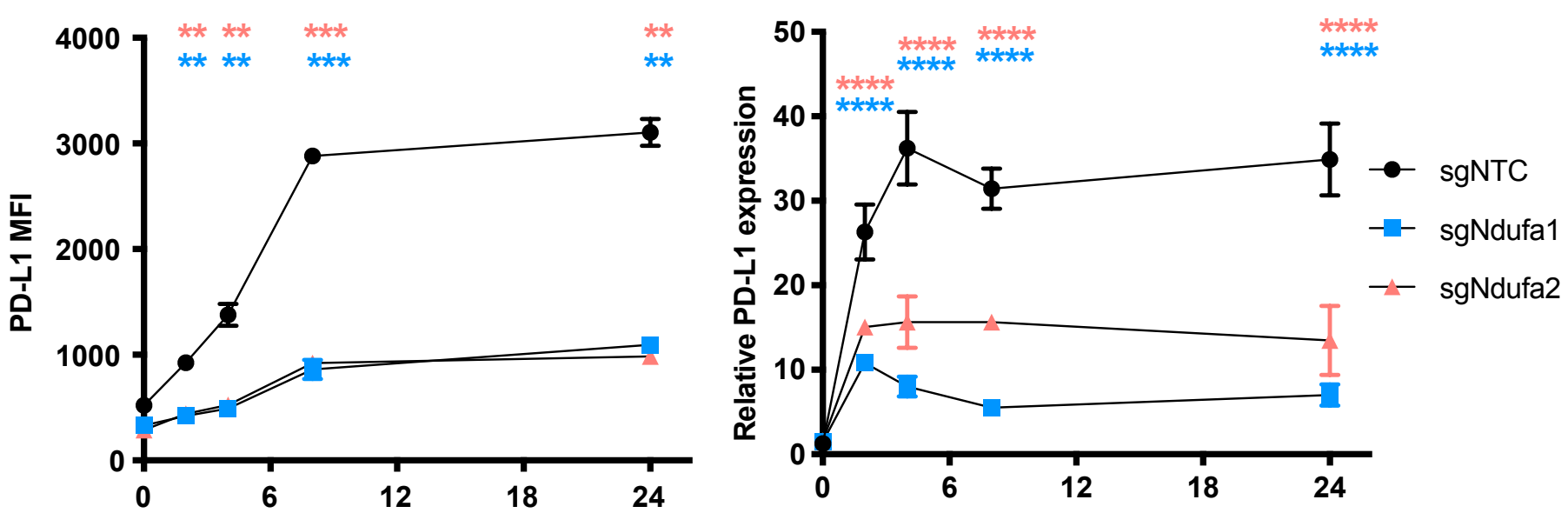

B

Hours

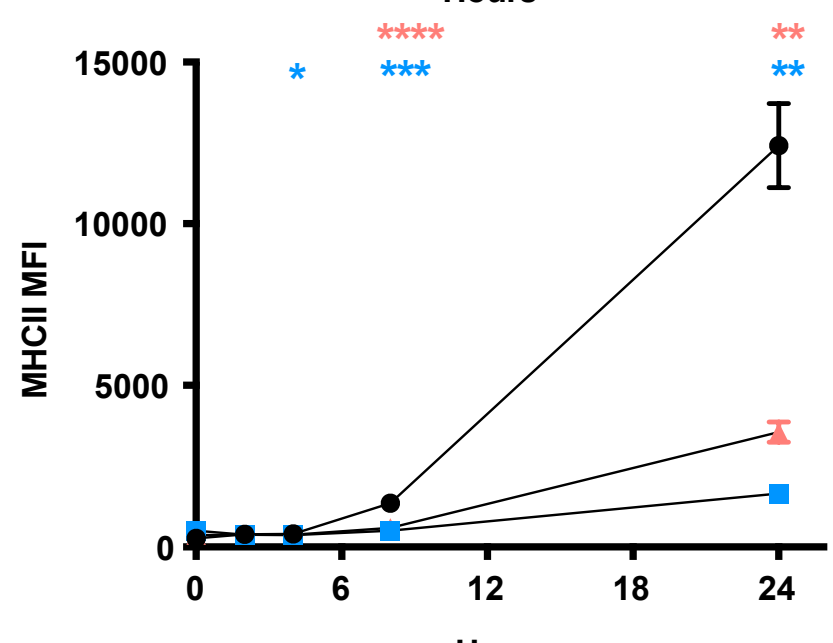

Hours

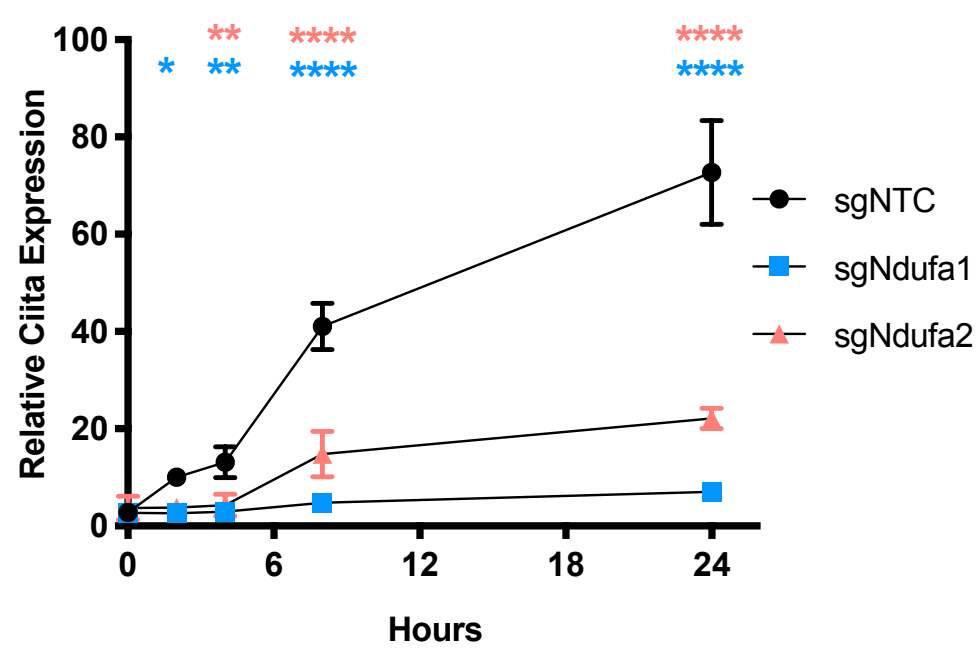

C

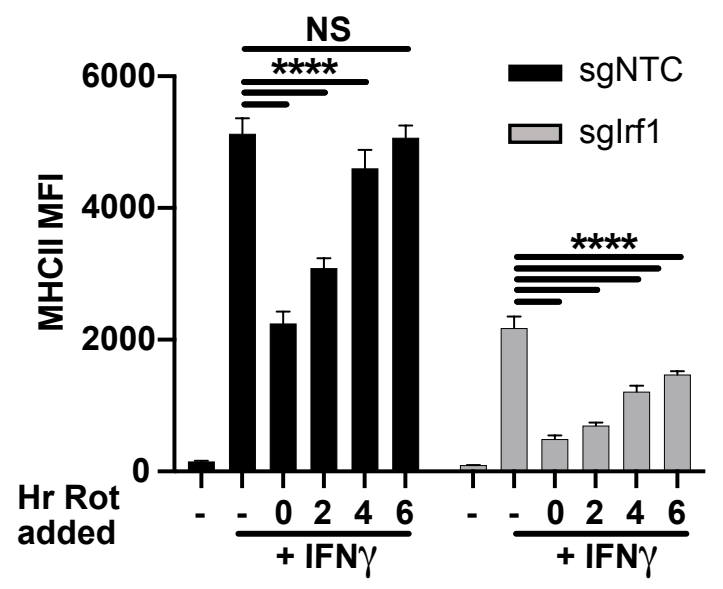

D
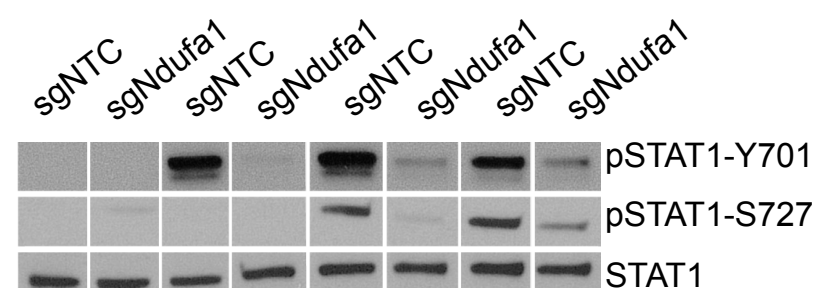

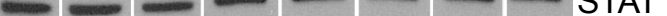

pJAK2-Y1007/8

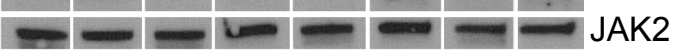

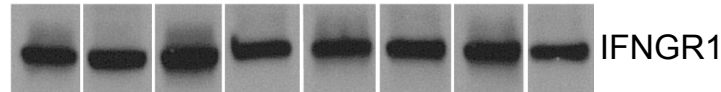

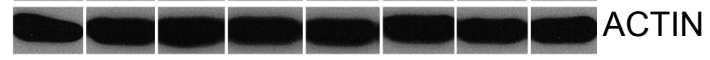

$\mathrm{IFN} \gamma-\quad \frac{\boldsymbol{+}+\boldsymbol{+}}{5 \min } \frac{\boldsymbol{+}+\boldsymbol{+}}{30 \min } \frac{\boldsymbol{+}}{60 \min }$ 
bioRxiv preprint doi: https://doi.org/10.1101/2020.11.22.393538; this version posted November 23,2020 . The copyright holder for this preprint (which was not certified by peer review) is the author/funder, who has granted bioRxiv a license to display the preprint in perpetuity. It is made available under aCC-BY-ND 4.0 International license.

A

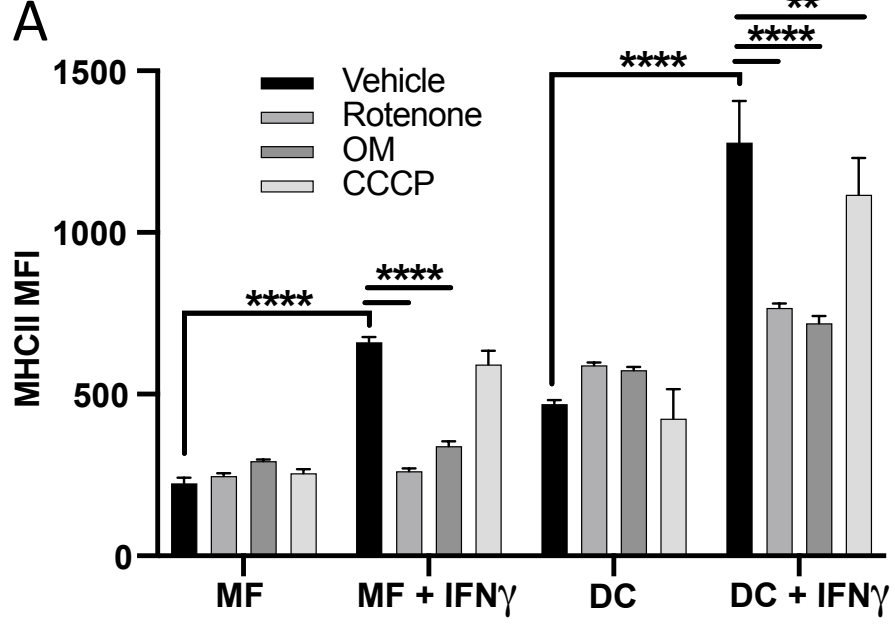

C
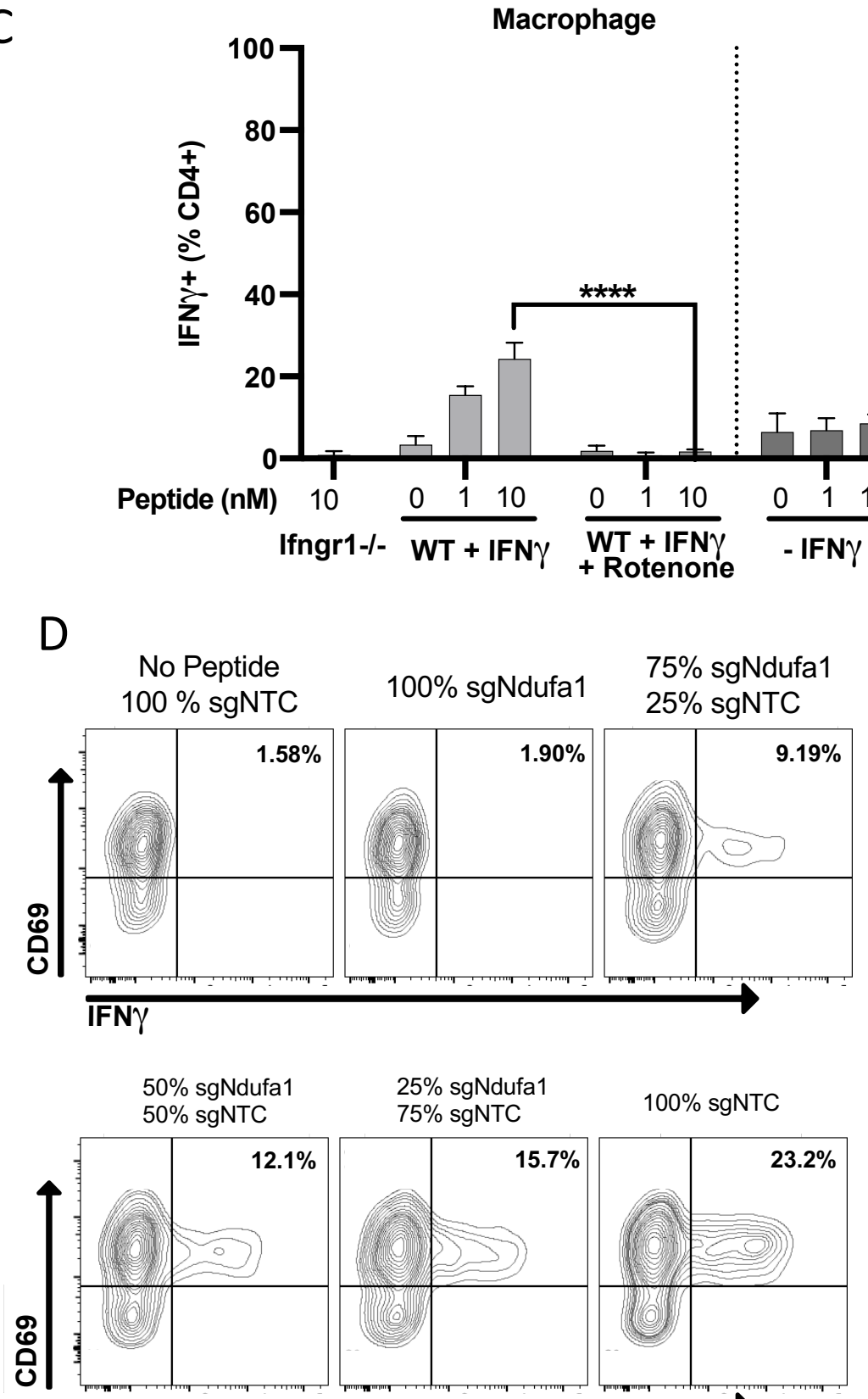

IFN $\gamma$
B

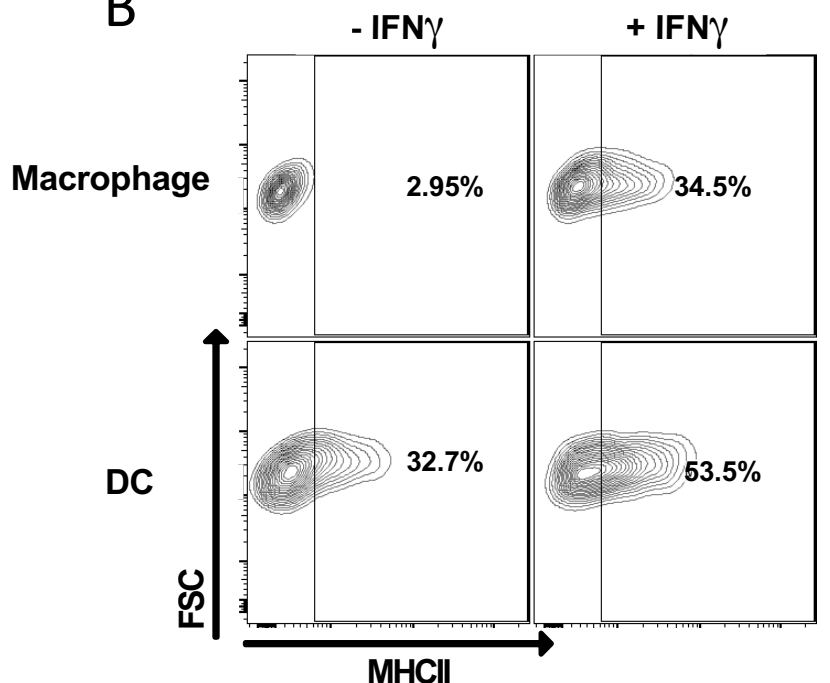

Dendritic Cell

E

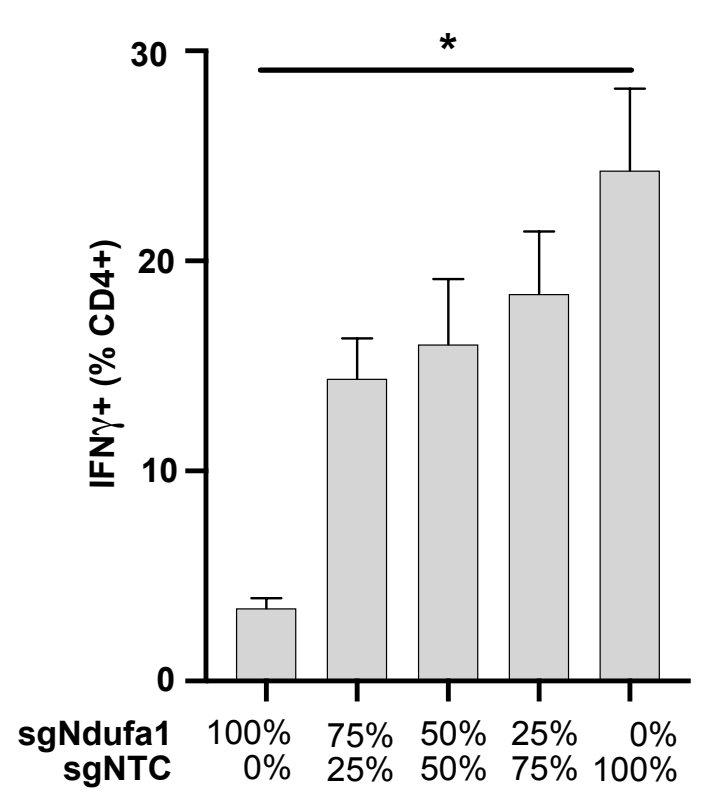


bioRxiv preprint doi: https://doi.org/10.1101/2020.11.22.393538; this version posted November 23, 2020. The copyright holder for this preprint (which was not certified by peer review) is the author/funder, who has granted bioRxiv a license to display the preprint in perpetuity. It is made Supplemental Figure 1

A

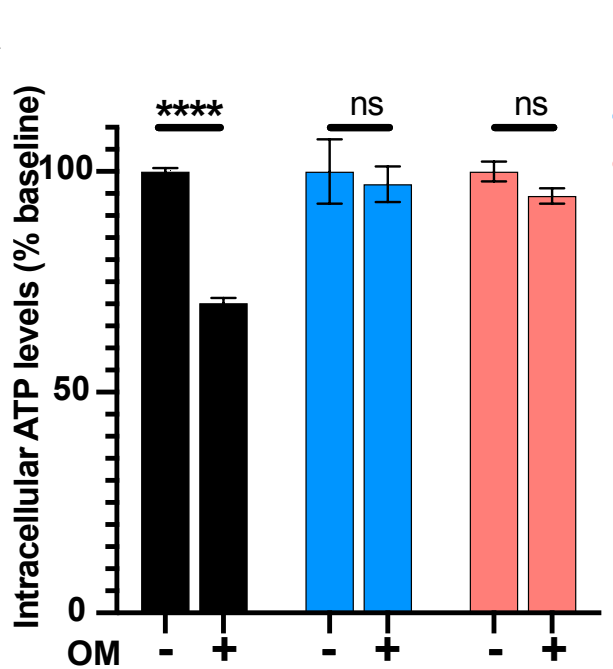
available under aCC-BY-ND 4.0 International license. 
bioRxiv preprint doi: https://doi.org/10.1101/2020.11.22.393538; this version posted November 23, 2020. The copyright holder for this preprint (which was not certified by peer review) is the author/funder, who has granted bioRxiv a license to display the preprint in perpetuity. It is made Supplemental Figure 2
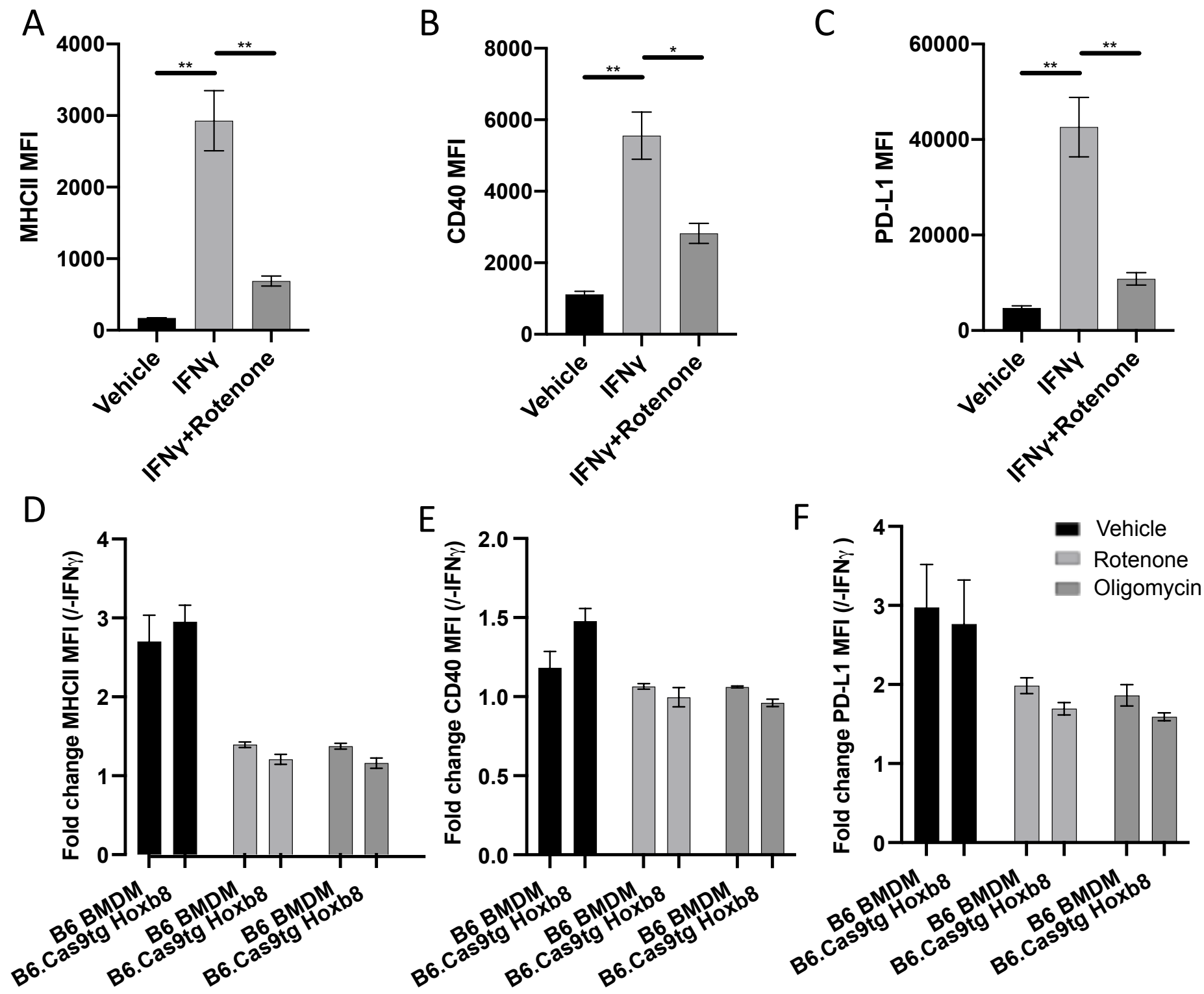

G

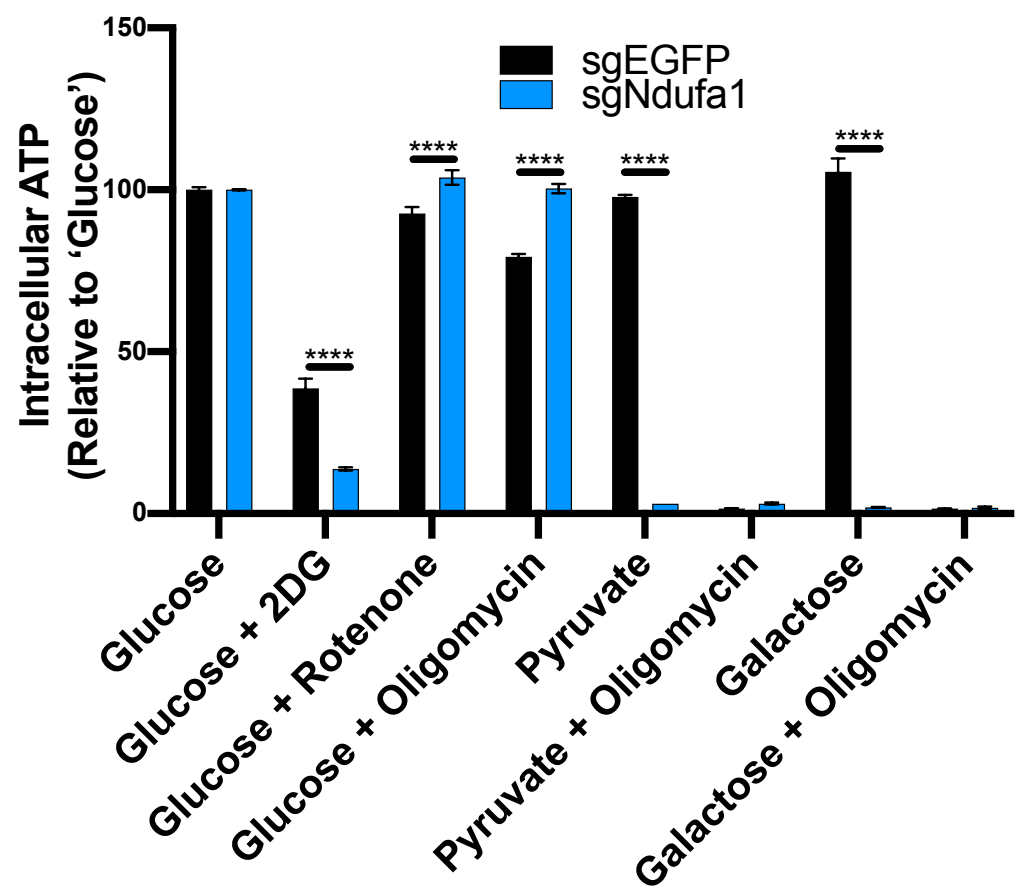

